Florida International University FIU Digital Commons

4-3-1995

\title{
The refinement and validation of the critical decision making and problem solving scale moral dilema (CDP-MD)
}

Ondina Arrufat

Florida International University

DOI: $10.25148 /$ etd.FI14032350

Follow this and additional works at: https://digitalcommons.fiu.edu/etd

Part of the Psychology Commons

\section{Recommended Citation}

Arrufat, Ondina, "The refinement and validation of the critical decision making and problem solving scale moral dilema (CDP-MD)" (1995). FIU Electronic Theses and Dissertations. 1426.

https://digitalcommons.fiu.edu/etd/1426 
FLORIDA INTERNATIONAL UNIVERSITY

Miami, Florida

THE REFINEMENT AND VALIDATION OF THE CRITICAL DECISION MAKING AND PROBLEM SOLVING SCALE - MORAL DILEMMAS (CDP-MD)

A thesis submitted in partial satisfaction of the requirements for the degree of MASTER OF SCIENCE

IN

PSYCHOLOGY

by

Ondina Arrufat 
This thesis, written by Ondina Arrufat, and entitled The Refinement and Validation of the Critical Decision Making and Problem Solving Scale - Moral Dilemmas (CDP-MD), having been approved in respect to style and intellectual content, is referred to you for judgement.

We have read this thesis and recommend that it be approved.

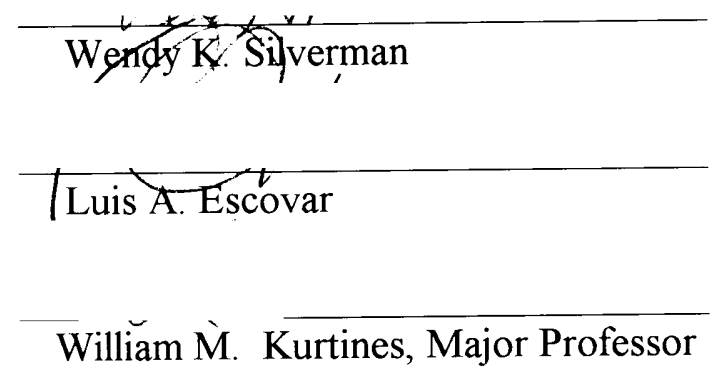

Date of Defense: April 3, 1995

The thesis of Ondina Arrufat is approved.

Deaf Arthur W. Herriott
College of Arts and Sqjences
Dr. Richard Campbell
Dean of Graduate Studies

Florida International University, 1995 
I dedicate this thesis to the memory of my father, who never doubted that I could do it; to my mother, whose only wish was to see me doing it; and to my daughter, who couldn't wait for the day that it was done. 


\section{ACKNOWLEDGMENTS}

I wish to thank the members of my committee for their help and understanding: Dr. Silverman, whose love for what she does was an inspiration and Dr. Escovar for making that one degree of difference.

I also want to thank all the members of the Psychosocial Development Lab. Thanks to all of you for putting up with me and my craziness. A heartfelt thank you goes to Steve Berman, for without his shoulder to lean on I may not have survived to see this work completed.

A special thanks goes to my major professor, Dr. Kurtines, for having the confidence in me that I sometimes lacked. Without your help and guidance this thesis may have never been done. 


\begin{abstract}
OF THE THESIS
THE REFINEMENT AND VALIDATION OF THE CRITICAL DECISION MAKING

AND PROBLEM SOLVING SCALE - MORAL DILEMMAS (CDP-MD)

by
\end{abstract}

Ondina Arrufat

Florida International University, 1995

Miami, Florida

Professor William M. Kurtines, Major Professor

This thesis extended previous research on critical decision making and problem solving by refining and validating a measure designed to assess the use of critical thinking and critical discussion in sociomoral dilemmas. The purpose of this thesis was twofold: 1) to refine the administration of the Critical Thinking Subscale of the CDP to elicit more adequate responses and for purposes of refining the coding and scoring procedures for the total measure, and 2) to collect preliminary data on the initial reliabilities of the measure. Subjects consisted of 40 undergraduate students at Florida International University. Results indicate that the use of longer probes on the Critical Thinking Subscale was more effective in eliciting adequate responses necessary for coding and evaluating the subjects performance. Analyses on the psychometric properties of the measure consisted of testretest reliability and inter-rater reliability. 


\section{TABLE OF CONTENTS}

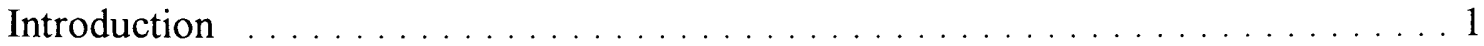

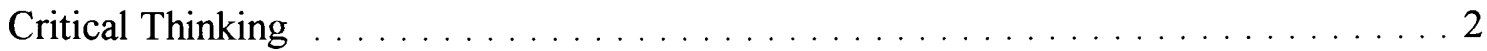

Critical Thinking in Problem Solving $\ldots \ldots \ldots \ldots \ldots \ldots \ldots$

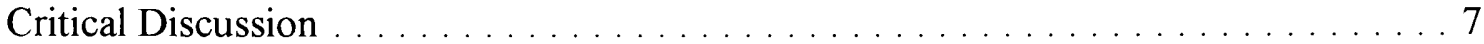

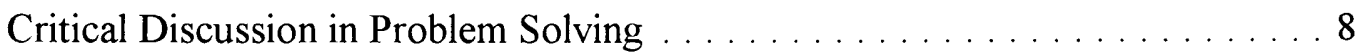

The Development of a Critical Sociomoral Orientation $\ldots \ldots \ldots \ldots \ldots \ldots$

Previous Research . . . . . . . . . . . . . . . . . . . . . . . 13

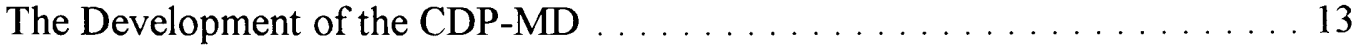

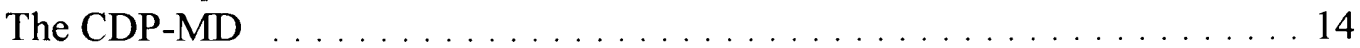

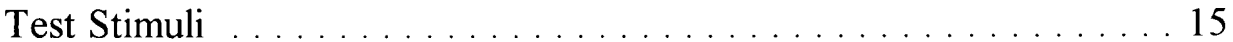

The CDP-MD Subscales . . . . . . . . . . . . . . . . 16

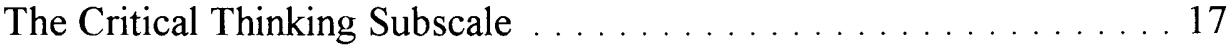

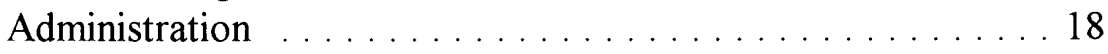

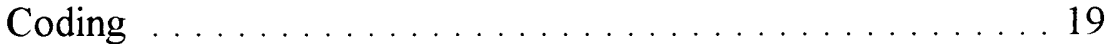

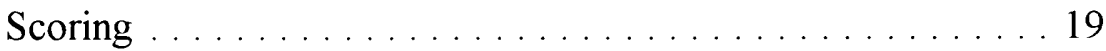

The Critical Discussion Subscale . . . . . . . . . . . . . . . 20

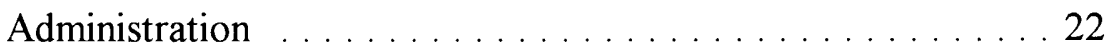

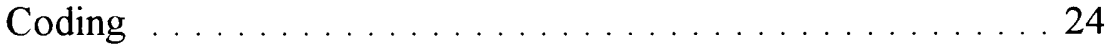

Scoring . . . . . . . . . . . . . . . . . . . . 24

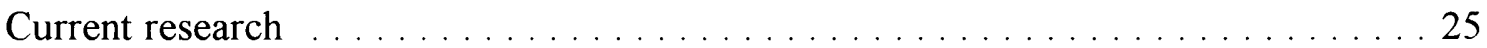

The Refinement of the CDP-MD . . . . . . . . . . . . . . . . . . . 25

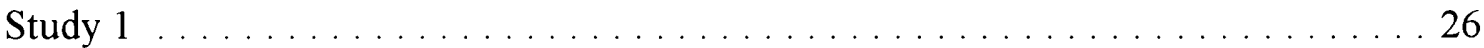

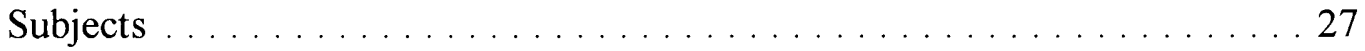

Procedure ................................ 27

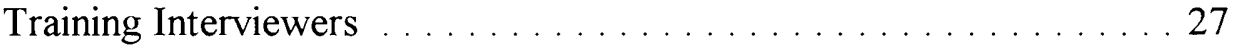

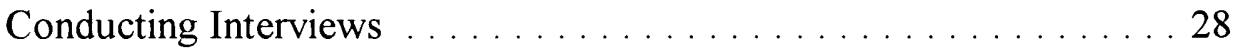

Training coders . . . . . . . . . . . . . . . . . . . . 28

Results . . . . . . . . . . . . . . . . . . . . . . . . . . . . . . . . 29

Conclusion . . . . . . . . . . . . . . . . . . . . . . . . . . . . . . 29

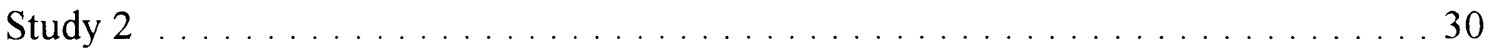

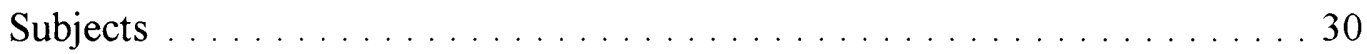

Procedure ................................. 30

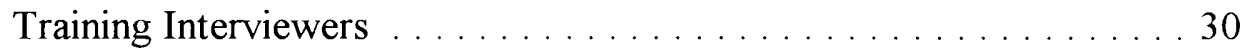

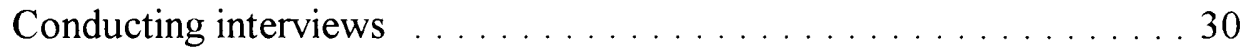

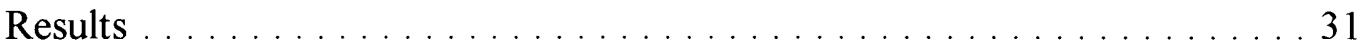

Psychometric Analysis . . . . . . . . . . . . . . . . . . . . . . 32 
Item Analysis . . . . . . . . . . . . . . . . . . . . . . . 32

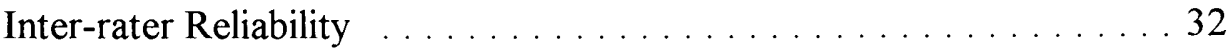

Retest Reliability . . . . . . . . . . . . . . . . . . . 32

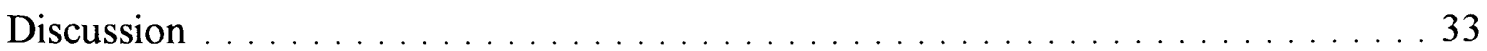

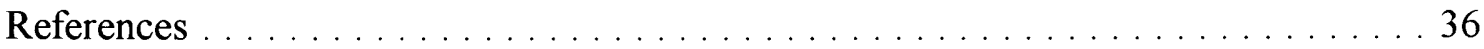

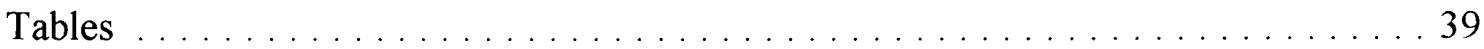

Appendixes .................................. 43

Appendix A

Moral Dilemmas-Interview/Protocol Worksheet . . . . . . . . . . . . . . 44

Appendix B

CDP-MD Rating Form

Appendix C

Coding the CDP-MD

Appendix D

Administering Part II of the CDP-MD 


\section{LIST OF TABLES}

Table 1

Comparison of response times. . . . . . . . . . . . . . . . . . . 40

Table 2

Patterns of Global Scores. . . . . . . . . . . . . . . . . . . . . . . 41

Table 3

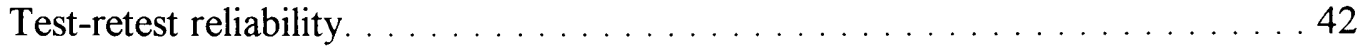




\section{Introduction}

The project described in this thesis was derived from an ongoing program of psychosocial theory and research (Kurtines, Berman, Ittel, \&Williamson, 1995; Kurtines, 1984; 1987; 1990; Kurtines, Mayock, Pollard, Lanza, \& Carlo, 1991; Pollard, Kurtines, Carlo, Dancs, \& Mayock, 1991) that provides a framework for conceptualizing the role that critical thinking and critical discussion plays in human decision making and problem solving. This framework conceptualizes critical thinking and critical discussion as involving specific types or categories of decision making and problem solving operations and actions that human beings use in individual and group decision making and problem solving activities.

Critical thinking and discussion are conceptualized as involving complex, higher order types of decision making and problem solving operations and actions that occur relatively infrequently in ordinary decision making and problem solving. However, although they occur infrequently, they are important in human decision making and problem solving because of the role they play when ordinary decision making and problem solving activities fail. They are an important part of human decision making and problem solving because of the role that they play in resolving difficulties that go beyond the range of ordinary decision making and problem solving activities. Critical thinking and discussion thus involve specific types of decision making and problem solving operations and actions that can be most usefully conceptualized within a broader framework that includes an account of the full range of operations and actions that play a role in human decision making and problem solving.

These complex cognitive and communicative competencies play an important 
role in the extraordinary adaptability of the human species. They are important to the adaptability of the human species because they enable human beings to generate and disseminate adaptive responses to changing conditions. The development and use of these higher order cognitive and communicative competencies enables human beings to engage in the most complex forms of theoretical and practical problem solving activities. These complex cognitive and communicative competencies are important because the extraordinary adaptability of the human species is rooted in the capacity to use these competencies in solving problems that arise with respect to human goal oriented behavior.

\section{Critical Thinking}

Much of the work on critical thinking has been on the development and use of logical reasoning skills in problem solving and decision making (Glaser, 1984). However, a number of concerns have been raised about the degree to which logical reasoning skills encompass the full range of skills involved in critical thinking. Brabeck and Wood (1985), for example, have pointed out that logical reasoning skills are particularly useful in solving "well-structured" problems. Well structured problems are characterized by having known problem characteristics or properties that lead to single verifiable and certain answers. Many real-world problems, however, are complex or "illstructured" problems (Churchman, 1971) for which there is often conflicting or incomplete information, have unknown, unspecifiable or even conflicting problem characteristics, and lead to more than one of a number of solutions that are neither certain nor verifiable. Such problems often involve the use of more than logical reasoning skills; they involve other types of higher order reasoning processes. Kitchener 
and King (1981), for example, have proposed that reflective judgement is also an important higher order type of cognitive skill. Reflective judgements are not concerned with logical problem solving skills; rather, reflective judgements concern the nature of the epistemological and metaphysical assumptions that affect the ways people use evidence and justify beliefs.

The conceptualization of critical thinking in problem solving and decision making used in this project draws on the consensus that has begun to emerge in the literature with respect to the general features of a broader, more practical conception of critical thinking. First, critical thinking is generally recognized as a higher order cognitive capacity and thus similar to other types of higher order cognitive abilities (Glasser, 1984). Critical thinking, for example, includes the capability of monitoring and evaluating one's own performances, i.e., thinking about thinking (Greeno, 1989), and is thus a type of meta-cognition (Bransford, Sherwood, Vye, \& Rieser 1986). Critical thinking, however, involves more than meta-cognitive processes.

Critical thinking is a complex, higher order type of cognitive process that facilitates problem solving activities in contexts of disequilibrium. That is, critical thinking is a higher order type cognitive process that facilitates generating adaptive responses under changing conditions. This section will outline the conceptualization of critical thinking used in the project. The section begins by describing the type of activities normally involved in human goal oriented behavior. It then describes the types of activities involved in solving problems that arise with respect to human goal oriented behavior. This description provides the framework for outlining a conceptualization of the role that critical thinking plays in these problem solving activities. 
As a self-directed, goal oriented biopsychosocial organism, the human species, like other species, is confronted with the task of maintaining an equilibrium with its environment. Under conditions of equilibrium, human goal oriented behavior is oriented toward goals actually or potentially attainable under existing conditions and toward maintaining the equilibrium necessary for achieving those goals. Goal oriented behavior involves both means and ends. Ends refers to goals, aims, outcomes, etc. and means refers to the plans, procedures, methods, strategies, etc. by which goals, aims, or outcomes are achieved or accomplished. Problems arise with respect to human goal oriented behavior when changing organismic and/or environmental conditions create a disequilibrium that disturbs, interrupts, or disrupts goal oriented behavior. Because goal oriented behavior involves both means and ends, problems can arise with respect to either means or ends or both.

The disequilibrium created by changing conditions results in two basic types of problems with respect to human goal oriented behavior: instrumental and normative. A problem is instrumental when it involves the means or method by which goals or ends are (or can be) achieved. A problem is normative when it involves the desirability (goodness, rightness, usefulness, etc.) of the goals or ends themselves. Thus, changing conditions create a disequilibrium that challenges the utility of means or methods and/or the validity of goals or ends and disturbs, interrupts, or disrupts goal oriented behavior. Successful problem solving involves establishing or reestablishing an equilibrium that restores successful goal oriented behavior. The three basic types of activities involved in successful problem solving are briefly described next.

First, successful problem solving involves recognizing when a problem exists. 
Recognizing when a problem exists includes not only recognizing that goal oriented behavior has been disturbed, interrupted, or disrupted, but also identifying and rendering explicit the nature of the problem. This includes identifying whether the problem is instrumental, normative, or both and identifying and rendering explicit the problematic means or methods and/or goals or ends. Successful problem solving, however, requires more than recognizing that a problem exists and what the problem is. Successful problem solving also involves generating potential alternatives (instrumental or normative) for resolving the problem and restoring equilibrium. If the problem is instrumental, generating alternatives involves either transforming or reconstructing and/or inventing or creating new or novel means or methods for achieving goals and ends. If the problem is normative, generating alternatives involves either transforming or reconstructing and/or inventing or creating new or novel goals and ends themselves. Finally, successful problem solving also involves evaluating, selecting, and implementing the most adaptive alternatives from among the competing means or methods and/or goals or ends. Successful problem solving thus involves three basic activities: 1) recognizing when a problem exists and identifying what the problem is, 2) generating alternatives for solving the problem, and 3) selecting the most adaptive alternative.

Critical Thinking in Problem Solving. Now that the types of activities involved in successful problem solving have been outlined, we can turn to the role that critical thinking plays in these activities. This view of the role that critical thinking has to play in problem solving activities, draws on the consensus that has emerged in the literature with respect to a more practical conception of critical thinking. As Greeno (1989) has noted, critical thinking is reflective thinking rather than simply accepting 
statements and carrying out procedures without significant understanding and evaluation.

Critical thinking involves being able to recognize circumstances when reflection and evaluation might be useful in overcoming some difficulty that has emerged in the normal course of activity and taking steps to resolve the difficulty. Critical thinking is thus a complex, higher order type of cognitive process that should not be expected to occur at all times (Greeno, 1989).

As it applies to individual problem solving, critical thinking involves two basic processes: suspension of judgment and critical evaluation. These two processes have an important role to play in all three types of problem solving activities. Suspension of judgment involves treating the problem hypothetically and entertaining the possible utility and/or validity of all potential interpretations with respect to what the problem is, what the alternatives are, and what the best solution is. Critical evaluation involves challenging, questioning, and subjecting to critical examination all potential interpretations as to what the problem is, what the alternatives are, and what the best solution is. Critical thinking is thus thinking that involves adopting a critical (i.e., skeptical or questioning) stance with respect to the problem to be solved, including all activities related to successfully solving the problem.

The use of critical thinking in problem solving has an important role to play in successfully solving problems that arise with respect to human goal oriented behavior because it facilitates the resolution of challenges to the utility or validity of the goal oriented behavior. With the development of the capacity for critical thinking, the individual acquires the capacity for a type of problem solving that is unique to the human species. The capacity for critical thought enables human beings to do more than solve 
problems that arise with respect to goal oriented behavior. The capacity for critical thought enables human beings to challenge or question the utility of the means or methods by which goals are achieved and to transform or reconstruct them and/or to invent or create new ones when necessary. More importantly, the capacity for critical thought enables human beings to challenge or question the value or validity of goals or ends themselves and to transform or reconstruct them and/or to invent or create new ones when necessary. The development of the capacity for critical thought thus not only enables the individual to engage in complex forms of problem solving. It is also one of the complex, higher order capacities that enable human beings to transform or reconstruct and/or to invent or create the goals and values that shape and influence the direction of personal change.

\section{Critical Discussion}

Although there is a relatively large research literature on critical thinking (Greeno, 1989; Norris \& Ennis, 1989; Norris, 1989; Siegel, 1988; Young, 1980), relatively little research has been done in the area of critical discussion. Consequently, the conceptualization and operationalization of the concept of critical discussion as part of this program of research has drawn on the research that has been done on critical thinking.

Critical discussion is in many respects similar to critical thinking. Critical discussion is a complex, higher order type of communicative process that comes into play when ordinary communication processes are unable to solve problems and resolve difficulties. Critical discussion is also similar to critical thinking in that it is a type of meta-communicative process that includes communication about communication. 
Critical discussion is also similar to critical thinking in that critical discussion a communicative process that comes into play in resolving problems that arise with respect to goal oriented behavior. Finally, critical discussion is similar to critical thinking in that it plays a role in the three basic types of problem solving activities, i.e., recognizing when a problem exists and identifying what the problem is, generating alternatives for solving the problem, and selecting the most adaptive alternative.

Although critical thinking and critical discussion are in many respects similar, they are different processes. Critical thinking is a cognitive process. Cognitive processes are intrapersonal processes -- they take place within the individual. Critical discussion, on the other hand, is a communicative process. Communicative processes are interpersonal -- they take place between two or more individuals. Critical thinking has an important role to play in solving problems that arise with respect to both individual and group goal oriented behavior. ${ }^{1}$ Solving problems that arise with respect to group goal oriented behavior, however, requires more than the use of critical cognitive processes in problem solving activities. Successful group goal oriented behavior also requires communication.

Critical Discussion in Problem Solving. Critical discussion is a type of communicative process that comes into play in solving problems that arise with respect to group goal oriented behavior. Social groups, like the individuals who comprise them, engage in goal oriented behavior. Moreover, as with individual goal oriented behavior, problems arise when changing conditions challenge or call into question group goals

\footnotetext{
${ }^{1}$ The term "group" in the generic sense refers to human social systems of all sizes and degrees of complexity, i.e., small groups, large groups, families, social networks, social institutions, nations, societies, and cultures.
} 
and/or methods for achieving them. Changing conditions create a disequilibrium in which competing goals and/or methods challenge existing goals or methods. In this respect, resolving challenges to group goal oriented behavior presents a more complex problem than resolving challenges to individual goal oriented behavior because a successful resolution requires a consensual resolution. That is, a successful resolution to a challenge to group goal oriented behavior requires not only a resolution to the challenge, but a resolution for which there is consensual agreement. The successful resolution of a challenge to group goal oriented behavior requires the establishment or re-establishment of a shared understanding with respect both to the validity and utility of group goal oriented behavior.

Because the achievement of group goals requires communication, it was necessary to go beyond the literature on critical thinking. The work in the area of critical discussion was drawn from Habermas' communication theory (McCarthy, 1981). Critical discussion is conceptualized within the broader framework of Habermas's theory of communicative action. In this frame, critical discussion is viewed as a complex, higher order type of communicative process that occurs relatively infrequently in ordinary communication. However, although it occurs infrequently, it is an important mode of communication because it occurs when ordinary communication fails to solve problems or resolve difficulties. It is important because of the role that it plays in solving problems and resolving difficulties that go beyond the range of ordinary communication processes.

As it applies to group problem solving, critical discussion involves the same two basic processes as critical thinking: suspension of judgment and critical evaluation. As 
with critical thinking, these two processes have an important role to play in all three types of problem solving activities. Critical discussion is thus similar to critical thinking in that it involves adopting a critical (skeptical, questioning, etc.) stance. Moreover, critical thinking provides the basis for critical discussion. Without critical thinking there can be no critical discussion. As noted, however, critical discussion is not the same as critical thinking. Critical thinking is a cognitive process and critical discussion is a communicative process. Critical discussion is discussion that entertains the possible utility and/or validity of all potential interpretations with respect to what the problem is, what the alternatives are, and what the best solution is. Critical discussion is also discussion that is open to questions or challenges with respect to all potential interpretations as to what the problem is, what the alternatives are, and what the best solution is. The use of critical discussion in group problem solving has an important role to play in successfully solving problems that arise with respect to group goal oriented behavior because it facilitates the resolution of challenges to the utility or validity of group goal oriented behavior.

The conceptualization of critical discussion draws on both the literature on critical thinking and recent work in the area of human communication. Like the capacity for critical thinking, the capacity for critical discussion enables human beings to do more than engage in goal oriented behavior. The capacity for critical discussion enables human beings to challenge or question the utility of the means by which group goals are achieved and to transform them and/or create new ones when necessary. More importantly, the capacity for critical discussion enables human beings to challenge or question the value or validity of group goals or ends themselves and to transform them 
or to create new ones when necessary. The development of the capacity for criticaldiscursive action thus not only enables human beings to engage in complex forms of group problem solving, it is also one of the complex, higher order capacities that enable human beings to transform or reconstruct and/or to invent or create the group goals and values that shape and influence the direction of historical change.

\section{The Development of a Critical Sociomoral Orientation}

The conceptualization of critical thinking and discussion described above provides the foundation for all of the work on developing a measure of critical thinking and discussion. The conceptualization of the development of a critical sociomoral orientation described in this section provides the specific framework for developing a measure of the use of critical competencies in moral decision making and problem solving. This framework has been described in more detail elsewhere (e.g., Kurtines, 1995).

According to this view, sociomoral development involves the two basic types of intraindividual change. The first type of change involves the acquisition of the content of the individual's sociomoral understanding. Content refers to the specific moral rules, norms, standards, values, and principles that make up the individual's sense of morality. According to this theory of moral development, the basic content of the child's sense of morality is acquired from the child's culture early in life through a process of learning (e.g., conditioning, imitation, modeling, etc.). ${ }^{2}$

\footnotetext{
${ }^{2}$ The process of cultural transmission is an imperfect one. The child's culture influences the content of the child's morality, but the child also has an influence on the content of the culture's morality. The developing child contributes to the transformation/ creation of the cultural content of morality in the form of the transformation/reconstruction and the invention /creation of novel interpretations of sociomoral rules.
} 
The second type of change involves the individual's orientation toward the content of morality, i.e., the type of cognitive and communicative processes the individual uses in making moral decisions -- decisions about what is right and what is wrong. This type of change involves developmental transformations of the individual's capacity to adopt a critical orientation toward the moral rules, norms, standards, values, and principles that $\mathrm{s} /$ he uses in making moral decisions. The development of a critical sociomoral orientation involves the development of the capacity to use critical thinking and critical discussion in individual and group moral decision making and problem solving. That is, a critical sociomoral orientation involves the use of critical competencies in resolving conflict that arises with respect to the utility and/or validity of sociomoral rules, norms, standards, values, and principles.

The development of a critical sociomoral orientation is thus viewed as linked to the development of more underlying critical cognitive and communicative competencies. With the acquisition of a critical orientation the individual can use critical thinking in making decisions about needs, interests, expectations, rules, norms, values, and standards now capable of being viewed as hypothetical. The individual can also use critical discussion in solving problems and making decisions about normative claims, now viewed as open to critical examination, negotiation, discursive redemption, and co-construction. The development of a critical sociomoral orientation thus enables human beings to make decisions, solve problems, and resolve difficulties with respect to the utility and/or validity of moral rules, norms, standards, values, and principles and to transform or reconstruct them and/or to invent or create new ones when necessary. 


\section{Previous Research}

\section{The Development of the CDP-MD}

The Critical Decision Making and Problem Solving Scale -- Moral Dilemma (CDP-MD) is designed to be used for assessing developmental and individual differences in the use of critical thinking and critical discussion in moral decision making and problem solving. The development of the administration and scoring procedures for the moral dilemma form of the CDP (i.e., the CDP-MD) involved three studies. The first study by Williamson (1992) focused on the development of a measure of Critical Cognitive Style in moral decision making and problems solving. The second study by Pollard (1991) focused on the development of a measure of Critical Communicative Style in moral decision making and problems solving. The third study by Davis (1993) focused on integrating the measures of critical thinking and discussion into a single format.

The Williamson study (Williamson, 1992) reported the development and refinement of a measure of critical cognitive style designed to assess critical thinking in sociomoral dilemmas. The subjects for the study consisted of 72 young adult college students. The Williamson study described the development of the administrative format, test stimuli, and the coding/scoring procedures for the measure of critical cognitive style that provided the basis for the critical thinking part of the CDP-MD.

The Pollard study (Pollard, 1991) reported the development and refinement of a measure of critical communicative style designed to assess critical discussion in sociomoral dilemmas. The subjects for the study consisted of 138 young adult college students. The Pollard study described the development of the administrative format, test 
stimuli, administration procedure, and the coding/scoring procedures for the measure of critical cognitive style that provided the basis for the critical discussion part of the CDPMD.

The Davis study (Davis, 1993) reported the development and refinement of the CDP-MD, a measure that integrates the scales developed in the Pollard and Williamson studies into a single format. The subjects for the study consisted of 6 young adult college students. The Davis study described the preliminary development of the administrative format, test stimuli, administration procedure, and the coding/scoring procedures for the CDP-MD. The measure that will be used in the study builds on these three previous studies.

\section{The CDP-MD}

This section describes the measure that was developed as part of the pilot work. This version of the CDP-MD was developed as part of the above mentioned work and is the version that was evaluated in the proposed study. The CDP-MD consists of a two part, ten page protocol administered using an interview format. Part I, the Critical Thinking Subscale, was adapted from the measure of critical cognitive style reported by Williamson (1992). Part II, the Critical Discussion Subscale, was adapted from the measure of critical communicative style reported by Pollard (1991).

The specific procedures for administering, coding, and scoring the CDP-MD described here are intended for use with videotaped interviews which have been conducted using the Critical Decision Making and Problem Solving Scale - Moral Dilemma (CDP-MD) Manual (Kurtines, Arrufat, \& Davis, 1995). The CDP-MD interview uses the generic CDP format of sampling the operations and actions that a 
subject uses in decision making and problem solving. In this case, the CDP-MD samples the categories of decision making and problem solving operations and actions in making moral decisions and solving moral dilemmas.

Test Stimuli. The test stimuli for the CDP-MD consists of six situations involving fictional characters confronted with hypothetical moral dilemmas. The stimuli were adapted from the Moral Identity Scale (Kurtines, 1991). This scale was originally designed to assess individual, developmental, and cultural variation in value orientation. The value orientations the scale measures are a Deontological versus a Teleological orientation. A deontological orientation focuses on the importance of duty or obligation in moral choices; a teleological orientation focuses on the importance of outcome or consequence in moral choice.

The dilemmas from the MIS are about hypothetical characters (Hobbits). The following is an example from the MIS dilemma entitled, "Breaking a Promise":

After Rob had given both Sam and Dale their presents, the three Hobbits began to prepare dinner. And it was a splendid supper indeed, for all of the hard work and fresh air had given the Hobbits a hearty appetite. Later, while sitting on the porch, Sam told Rob that he had found a magic black mushroom in the field. Black mushrooms were said to have many different types of powers. It has been said that one bite of a black mushroom could make someone feel very happy. Black mushrooms, however, have also been said to make Hobbits act in strange ways, sometimes even causing them to harm themselves. Now, while Sam had a warm and friendly disposition, he was also noted for being 
very impulsive and for doing foolish things. Consequently, Sam asked

Rob to keep the black mushroom for him. However, before giving Rob the mushroom, Sam made Rob swear a double solemn oath, which Hobbits take very seriously, to give him the black mushroom back whenever he asked for it.

Later on in the evening, in the middle of a fitful sleep, Sam woke up. He had been feeling very bad about his father, and he asked Rob to give him the black mushroom back because he wanted to eat some. Rob was not sure about what to do so he considered his choices. On the one hand, he felt that he had an obligation to give him the mushroom back because he had made a solemn promise to do so. On the other hand, he felt that if he did give it back Sam might do something to hurt himself. If you were Rob, what would you $d o$ ?

1) Give the mushroom back.

2) Keep the mushroom.

Why?

All six situations present the same type of dilemma, a conflict between a prima facie moral obligation (e.g., telling the truth, keeping a promise, etc.) and a negative consequence for one of the characters. The problem the dilemmas present is thus one of conflicting moral obligations, and the subject has to decide which of the alternatives is the right thing to do.

The CDP-MD Subscales. The CDP-MD is made up of two parts, the Critical Thinking Subscale and the Critical Discussion Subscale. The subscales of the CDP-MD 
are designed to elicit samples of decision making and problem solving operations and actions when making both individual and shared moral choices. Consequently, as described in more detail below, each subscale has it own format.

The Critical Thinking Subscale of the CDP-MD is designed to sample the cognitive decision making and problem solving operations and actions the subject uses in resolving individual or personal moral dilemmas. It is administered as a standardized interview, and the dilemmas are presented as an individual decision making or problem solving situation (i.e., the subject has to decide what to do). The interviewer elicits the subject's account of his/her choice, and the subject's responses represented in the narrative account are coded for the categories of decision making and problem solving operations and actions the subject uses.

The Critical Discussion Subscale of the CDP-MD is designed to sample the communicative decision making and problem solving operations and actions the subject uses in resolving a group or shared moral dilemma. It is administered as a interactive interview, and the dilemmas are presented as a shared decision making or problem solving situation (i.e., the subject and the interviewer have to try to agree about what to do). The interviewer engages the subject in a discussion or dialogue involving his/her choice, and the subject's responses represented in the discussion are coded for the categories of decision making and problem solving operations and actions the subject uses.

\section{The Critical Thinking Subscale}

The Critical Thinking Subscale contains one page of standardized instructions and four additional pages, one for each of the four dilemmas, and an accompanying 
ratings code summary. The test stimuli for the Critical Thinking Subscale of the CDPMD consists of four of the hypothetical moral dilemmas adapted from the Moral Identity Scale (Kurtines, 1991). Appendix A gives the text for all 6 dilemmas.

Administration. The interviewer begins Part I by reading the subject the following directions:

In Part 1 of this interview we are interested in how people think when they are making decisions and solving problems involving moral choices. We are going to be discussing some moral dilemmas. I am going to read them to you one at a time and then ask you questions about what you would do and why you would make that decision. If you need to spend more time with the readings you are welcome to look at each one privately after I read it aloud. Any questions? Let's begin.

The interviewer then reads the first dilemma. Each dilemma ends with the question, "If you were Rob, what would you do?" and the cognitive probe, "Why"? The purpose of the cognitive probe is to elicit an account of the subject's cognitive decision making and problem solving operations and actions. After the subject responds to the cognitive probe, the interviewer follows up with three neutral elaboration probes (Could you tell me more? Is there anything else? Do you want to say more?) intended to furnish the opportunity for the subject to provide a more fully elaborated response.

Because the purpose of the probes is to elicit a sample of the full range of the subject's decision making and problem solving operations and actions, all of the probes

\footnotetext{
${ }^{3}$ Why? is a "cognitive" probe in contrast with other types of probes that might be used to elicit other types of responses. A probe such as, "How do you feel about your choice?", for example, might be used to elicit an account of the subject's affective state.
} 
are intended to be neutral with respect the content, form, or style of response they elicit. The aim of the probes is to allow the subject to use self-selected or self-generated categories of decision making and problem solving operations and actions in providing the narrative account of their choice. The cognitive and elaboration probes are thus designed to place as few limits or constraints on the subject's responses as possible in order to elicit as full a range of decision making and problem solving operations and actions as possible under conditions of an interview. The subject is first allowed to respond with as much elaboration as they like to the cognitive probe. When the subject has finished, the interviewer then prompts the subject with at least two of the three elaboration probes. That is, each subject is probed two times after the initial cognitive probe, giving them a total of three opportunities to respond.

Coding. The subject's responses represented in the narrative account generated by Part I of the CDP-MD are coded for categories of cognitive operations and actions adapted from the categories identified by Williamson (1992). The categories include: Justifications, Paraphrases, Reflections, Challenges, Entertainments, Modifications, and Integrations. Each of the categories is further coded for one of four category types: Dilemma Specific or Generalized and Factual or Normative. Each occurrence of the use of one of the categories is recorded on the Critical Thinking Subscale Rating Form (see Appendix B). Appendix $\mathrm{C}$ contains a detailed description of the coding categories for Part I of the CDP-MD. An understanding of these coding categories is necessary for administering the Critical Thinking Subscale of the CDP-MD.

Scoring. The Critical Thinking Subscale of the CDP-MD yields a raw score and a global critical score that provide information about the subject's use of the critical 
categories of decision making and problem solving operations and actions, i.e., Challenges, Entertainments, and Integrations. A Challenge is a statement that tests the validity of a previously stated choice and/or justification. An Entertainment involves the suspension of judgement with respect to the validity of both choices and/or justifications. An Integration is a statement that implicitly or explicitly attempts to satisfy both choices. A statement is coded as an Integration if it comes after the subject has reflected upon, challenged, or entertained the other choice and includes an explicit recognition of the other choice.

Raw Scores on the Critical Thinking Subscale of the CDP-MD consist of the total number of Challenges, Entertainments, and Integrations, i.e., the sum of all of Challenges, Entertainments, and Integrations across all of the dilemmas.

Global Scores on this Subscale of the CDP-MD consist of a classification of critical versus undifferentiated. Global scores are derived from the proportion of dilemmas that a scored as critical. More specifically, a dilemma is scored as critical if the subject uses one or more Entertainments or Integrations in that dilemma. The subject then receives a global score of critical if s/he receives a critical score on 3 out of 4 dilemmas.

\section{The Critical Discussion Subscale}

The Critical Discussion Subscale, contains one page of standardized instructions and eight additional pages, one for each of the four dilemmas, and one page for each of the accompanying ratings code summaries.

For the Critical Discussion Subscale, as for the Critical Thinking Subscale, the subject is presented with four sociomoral dilemmas. The Critical Thinking Subscale, 
however, is designed to assess the subject's use of critical thinking in an individual decision making context, and it uses a standardized interview in which the interviewer asks questions and probes to sample the subject's use of decision making and problem solving operations and actions. The subject responds to the probes and the subject's narrative account is coded for categories of decision making and problem solving operations and actions. The Critical Discussion Subscale, in contrast, is designed to assess the subject's use of critical discussion in an shared decision making context. This Subscale, therefore, uses a format, termed an "interactive interview," that is designed to sample the subject's use of decision making and problem solving operations and actions in a shared decision making context designed to simulate an actual discussion. The subject and the interviewer engage in a discussion or dialogue and the subject's segment of the discussion is coded for categories of decision making and problem solving operations and actions.

The simulated discussion format provides a sample of the subject's decision making and problem solving operations and actions in a shared decision making context under conditions that approximate those of an actual discussion while still providing some standardization and control. In an interactive interview the standardization and control are provided by having the interviewer match the type of decision making and problem solving operations and actions used by the subject. In an actual discussion (e.g., a peer dyadic discussion), one of the external contingent variables that influences the type of decision making and problem solving operations and actions that take place is the type of operations and actions the other participant uses. That is, a person is more likely to use the type of operations and actions characteristic of critical discussion when the 
other participant also uses the type of operations and actions characteristic of critical discussion, and less likely when the other participant in the discussion does not. Thus, in actual discussion, the other participant's type of communication places uncontrolled constraints on the use of critical communication.

In the interactive interview, because the interviewer matches the subject's operations and actions, the constraining effects of the other participant is minimized. The upper range of the type of operations and actions the subject uses is not constrained by the context of discussion because the interview protocol requires that the interviewer (i.e., the other participant) match the subject's type of operations and actions. The Critical Discussion Subscale of the CDP-MD thus elicits a sample of the subject's use of decision making and problem solving operations and actions in a shared decision making context while controlling for the communicative style/competence/performance of the other participant.

Administration. The interviewer begins Part I by reading the subject the following directions:

In Part 2 of the interview we are interested in how people talk about issues when they try to come to an agreement on what is the right thing to do. Because we have to suppose that there is a disagreement to start with, I will be taking the opposite choice on the dilemmas from whatever you take. Please make the choice that you would normally choose or the one which you feel is right. I will take the other choice and we will talk about the choices and try to come to some sort of an agreement about what to do. Any questions? We will begin by re-reading and discussing 
two of the previous dilemmas.

The interviewer then reads the first dilemma. Each dilemma ends with the question, "If you were Rob, what would you $d o$ ?" Part II, however, does not use the cognitive probe, "Why"? Instead, following each reading and after the subject has made a choice, the interviewer takes the opposite choice and begins the procedure of matching the subject's categories of response. The interviewer matches each response that the subject makes during each conversation turn by using the same category but with respect to the opposite choice on the moral dilemmas. For example, if the subject chooses the consequence alternative (not keeping the promise for the Breaking a Promise dilemma), the interviewer chooses the obligation alternative (keeping the promise). The interviewer then matches the subject's subsequent response by category and category type. If the subject justifies his/her own choice by making a factual claim (e.g., that the consequence will not occur), the interviewer matches with a similar factual justification but that justifies the interviewer's own choice (e.g., by making the opposite factual claim, i.e., that it will occur). If the subject attempts to clarify the interviewer's justification by constructively paraphrasing it, the interviewer matches by paraphrasing the subject's justification.

This matching procedure is followed until the criterion for completing the dilemma discussion is reached. The interviewer tracks the subject's responses (and the interviewer's) on the CDP-MD Interview Protocol/Worksheet (See Appendix A). The CDP-MD is thus designed to provide a sample of the subject's use of decision making and problem solving operations and actions in a shared decision making context condition that approximates that of an actual discussion while still providing some 
standardization and control. Appendix D provides for a more detailed description of the procedures for administering Part II of the CDP-MD. An understanding of these procedures is necessary for administering the Critical Discussion Subscale of the CDPMD.

Coding. The subject's responses represented in the discussion generated by Part II of the CDP-MD are coded for categories of decision making and problem solving operations and actions adapted from the categories identified by Pollard (1991) and reported in the CDP-MD manual. Each occurrence of the use of these categories is recorded on the CDP Critical Discussion Subscale Rating Form (see Appendix B). Appendix D contains a more detailed description of the procedure for administering and coding Part II of the CDP-MD, and also contains examples of prototypical justifications for obligation and consequence dilemma choices. An understanding of the procedures for administering Part II and a familiarity with the prototypical justifications and the coding categories is necessary for administering the Critical Discussion Subscale of the CDP-MD

Scoring. Raw Scores on Part II the CDP-MD are computed by adding the Entertainment and Integration scores and subtracting the Challenge score from the total sum. The result is then divided by the total number of Challenges, Entertainments, and Integrations within each dilemma (i.e., $\mathrm{E}+\mathrm{I} 1-\mathrm{C} 1 / \mathrm{E}+\mathrm{I} 1+\mathrm{C} 1$ ). These individual dilemma scores range from -1.00 to 1.00 . Scores ranging from -1.00 to -0.34 are labeled Argumentative, since the subject used more Challenges while scores ranging from 0.34 to 1.00 are labeled Accommodator, since there were more Entertainments and Integrations. Scores between -.34 and .34 are considered Critical because the subject 
tended to both Challenge and Entertain.

Global Scores on Part II of the CDP-MD consist of a classification of critical versus undifferentiated. Global scores are derived from the proportion of dilemmas that a scored as Critical. More specifically, the global score is computed by using the composite score from each dilemma. The subject receives a global score of "Critical" if $\mathrm{s} / \mathrm{he}$ receives a Critical score on 3 out of 4 dilemmas. If there are more Entertainments and Integrations than Challenges, the subject is labeled as "Accommodator". If there are more Challenges than Entertainments and Integrations, the subject is labeled as "Argumentative". A subject is labeled "Undifferentiated" if there were no Entertainments, Integrations, or Challenges.

\section{Current research}

\section{The Refinement of the CDP-MD}

Previous research on the development of the CDP-MD had developed administration and coding procedures for the measure. Although the Davis study had piloted the administrative format, test stimuli, administration procedure, and coding procedures for the CDP-MD, subsequent use of the measure indicated the need to further refine its format. In particular, although the Critical Discussion Subscale had elicited an adequate range of responses, the Critical Thinking Subscale did not elicit an adequate range of responses. Because the responses provide the basis for the coding categories, it was necessary to identify a method for eliciting longer responses with a more complete range of operations and actions. A number of alternatives were considered, and a decision was made to conduct a systematic study to refine the measure. More specifically, the purpose of this thesis was thus twofold: 1) to refine the 
administration of the Critical Thinking Subscale of the CDP to elicit more adequate responses and for purposes of refining the coding and scoring procedures for the total measure and 2) to collect preliminary data on the initial reliabilities and criterion related validity of the scale ${ }^{4}$.

\section{Study 1}

Study 1 was conducted primarily for the purpose of evaluating the effectiveness of a more comprehensive cognitive probe in eliciting a full range of responses on the Critical Thinking Subscale.

The cognitive probes that were used in the Davis study were:

If you were Rob what do you think you would do?

1) Have Dale pay more than Sam.

2) Have Sam pay more than Dale.

Why?
a) "Could you tell me more?"
b) "Is there anything else?"
c) "you want to say more?"

As already mentioned, these probes were not effectively eliciting an adequate range of responses. The new and more comprehensive probes tested in Study 1 were designed to remain neutral while at the same time present the subject with the opportunity to develop a more complete and extended answer. These probes were as follows:

\footnotetext{
${ }^{4}$ This study was developed and carried out at part of the program of research at the Psychosocial
} Development Lab of the Center for Child and Family Psychosocial Research, Florida International University. 
a) "In this study we are interested in finding out as much as we can about how people make choices. Therefore, we are especially interested in as much as you could tell us about how you made this choice"

b) "Are there any more details or information that you think might help us to understand how you made your choice?"

c) "Do you want to say more?"

Probes (a) and (b) were lengthier and more cumbersome for the interviewer to read on each dilemma and therefore were only used on the first dilemma. Because the effects of the instructional set were expected to carry over to the subsequent dilemmas, the more comprehensive probe was omitted on the next three dilemmas, resulting in the following:

a) "Are there any more details or information that you think might help us to understand how you made your choice?"

b) "Do you want to say more?"

c) "Is there anything else?"

\section{Subjects}

The subjects consisted of 20 undergraduate psychology students at Florida International University.

\section{Procedure}

Training Interviewers. Interviewers consisted of students registered for Independent Research credits in the Psychosocial Development Laboratory. All students were administered the CDP-MD prior to being trained. This was done for purposes of identifying potential interviewers as well as for acquainting the students with 
the procedures. Six interviewers were selected.

All selected interviewers were given the CDP-MD Manual to read and familiarize themselves with the procedures. Interviewers then attended two training meetings. The first meeting focused on reviewing the administration procedures described in the manual. All interviewers were shown videotapes of previous interviews showing good as well as bad techniques. The second meeting again reviewed the procedures described in the manual. Interviewers were then asked to role-play the administration of the interview.

Each interviewer was subsequently scheduled to administer an interview. His/her performance was later evaluated by the experimenter and feedback was provided in the form of suggestions for improvement as well as praise for adequate performance. In addition, the experimenter reviewed selected videotapes of all interviews to determine the consistency of administration for each interviewer.

Conducting Interviews. Subjects who agreed to participate were scheduled for interview appointments in the Psychosocial Development lab. All interviews were videotaped for purposes of coding and each interview lasted approximately 45 minutes. The measure was administered using the procedures already described.

Training coders. Coders consisted of students registered for Independent Research credits in the Psychosocial Development Laboratory. All students were administered the CDP-MD prior to being trained. This was done to acquaint the students with the interview format. Four students were selected as coders. Coding each interview took approximately 30 to 45 minutes.

All selected coders were given the CDP-MD Manual to read and familiarize 
themselves with the procedures. Coders were then trained to criteria during two training meetings. The first meeting focused on reviewing the coding procedures described in the manual. All coders were shown videotapes of previous interviews and coding procedures were reviewed. The coders were then asked to code one interview. The coding sheets were reviewed by the experimenter and feedback was given individually to each coder. The second meeting again reviewed the procedures described in the manual. At this meeting, coders were then asked to code an interview as a group. After each dilemma, all coders compared their ratings. Discrepant ratings were discussed and resolved by the experimenter. All of the data were coded and checked by the experimenter. Two subsequent meetings were scheduled for purposes of re-calibrating the coding procedures.

\section{Results}

Preliminary descriptive data analyses were conducted using the basic frequency descriptives. The results of these analyses indicated that the addition of the more comprehensive cognitive probe in the first dilemma elicited the desired range of responses. The subjects talked longer and tended to use more of the operations and actions that are coded on the CDP-MD. However, the expected carryover for the more comprehensive probe did not occur for the remaining three dilemmas. As a result, these three dilemmas did not elicit any better responses than those of the Davis study.

\section{Conclusion}

The results of Study 1 indicated that although the use of the more comprehensive probe for the first dilemma was effective in eliciting the desired range or responses, the overall performance of the measure in eliciting responses was still not adequate. A 
number of alternatives were considered. It appeared plausible that adding the more comprehensive probes to the remaining three dilemmas would consistently elicit more extensive responses. However, because a full range of responses to all of the dilemmas was a necessary precondition for conducting a psychometric analyses, it was essential to empirically test this hypothesis.

\section{Study 2}

Study 2 was conducted for the purpose of evaluating the effectiveness of the use of the more comprehensive cognitive probes for all four dilemmas as well as to conduct preliminary psychometric analyses on the CDP-MD.

\section{Subjects}

The subjects consisted of 20 undergraduate psychology students at Florida International University.

\section{Procedure}

Training Interviewers. Interviewers were selected and trained using the procedures described in Study 1.

Conducting interviews. Subjects were recruited in class and from students newly enrolled for research credits at the Psychosocial Development Lab. Subjects who agreed to participate were scheduled for interview appointments in the Psychosocial Development Lab. The interviews from this phase were be videotaped for purposes of coding the Critical Thinking Subscale. The measure was administered using the procedures already described. Ten of the subjects were administered the measure twice one week apart to investigate test-retest reliability, while the other 10 subjects were interviewed one time. 


\section{Results}

To evaluate the effectiveness of the of the use of the more comprehensive cognitive probes for all four dilemmas, the responses to the cognitive probes for dilemmas 2, 3, and 4 were timed for the length of the response. All tapes from Study 1 and Study 2 were reviewed and the duration of the response to the probes was recorded in seconds. Analyses of the mean response times for each dilemma indicate that there was a significant improvement in response duration when using the more comprehensive probe on Dilemma 2, $\underline{\mathrm{t}}(38)=4.61, \underline{\mathrm{p}}<.001$, Dilemma 3, $\underline{\mathrm{t}}(38)=4.17, \underline{\mathrm{p}}<.001$, and Dilemma $4, \underline{t}(38)=4.63, \underline{p}<.001$. Table 1 presents the duration data as well as the means and standard deviations for Dilemmas 2,3, and 4. The results of these analyses thus indicated that the addition of the more comprehensive cognitive probe for all of the dilemmas in Study 2 elicited the desired range of responses. The subjects talked longer and tended to use more of the operations and actions that are coded on the CDP-MD.

Preliminary descriptive analyses were conducted on the pattern of Global Scores for the CDP-MD. The most frequently occurring pattern (35\%) was Undifferentiated on Critical Thinking and Accommodating on Critical Discussion. The second most frequent pattern $(20 \%)$ was Undifferentiated on Critical Thinking and Argumentative on Critical Discussion. The least frequently occurring patterns were Undifferentiated on Critical Thinking and Critical on Critical Discussion (10\%), Critical on Critical Thinking and Accommodating on Critical Discussion (15\%), Undifferentiated on both Critical Thinking and Critical Discussion (10\%), and Critical on both Critical Thinking and Critical Discussion (10\%). Table 2 shows the frequency of these patterns. 


\section{Psychometric Analysis}

Item Analysis. A reliability analysis for the combined total of Accommodations and Integrations yielded the following results: for the Critical Thinking Subscale, Alpha $=.4648$ and for the Critical Discussion Subscale, Alpha $=.7400$. The analysis for the Challenges category for the Critical Discussion Subscale resulted in Alpha $=.3929$. There where not enough scores to perform an analysis for the Challenges category for the Critical Thinking Subscale.

Inter-rater Reliability. Inter-rater reliability was estimated by having two raters, working independently, code a random sample of $25 \%$ of the videotaped interviews using the CDP-MD scoring protocol. Inter-rater agreement was assessed by calculating the percentage of agreement between the raters for the raw scores and for the global scores for both subscales. For the Critical thinking Subscale, Cohen's kappa for the raw scores, $\mathrm{k}=.76$ and for the global scores, $\mathrm{k}=.61$ indicated an adequate agreement between raters. Results for the Critical Discussion Subscale for the raw scores, $\mathrm{k}=.28$ and for the global scores, $\mathrm{k}=.28$, were not significant.

Retest Reliability. Test-retest reliability was estimated by administering the CDP-MD to 10 subjects twice over a one week interval. An examination of the pattern of the Global Scores across both Parts I and II of the CDP-MD (See Table 3) indicated that $50 \%$ of the sample received exactly the same pattern of Global Scores on both Parts on both administrations. In addition, $40 \%$ of the sample matched on one of the two subscales. Only one subject had no match on either scale at either time. 


\section{Discussion}

The purpose of this research was to extend and refine our capacity to measure the use of critical thinking and critical discussion as conceptualized within the framework of a co-constructivist perspective. The goal of the study was to expand the work that has been done on the development of measures of critical thinking and critical discussion by going beyond the assessment of logical reasoning in the resolution of "well-structured" problems to the assessment of a disposition to suspend judgement and evaluate the validity of all possible alternatives. More specifically, this study sought to refine the administration of the CDP-MD, an instrument that combines measures of critical thinking and critical discussion, as well as to conduct preliminary analyses on the validity and reliability of the measure.

The results of Study 1 indicated the need to re-assess the cognitive probes being used to elicit responses from subjects. The spontaneous use of Entertainments, Challenges, and Integrations are infrequent in ordinary cognitive activity and thus eliciting a longer and more elaborate response may yield a more comprehensive range of responses. The inclusion of the more comprehensive cognitive prompt in Study 2 yielded the desired results. The subjects tended to talk longer and to render more elaborate answers in each of the dilemmas.

Study 1 also served to refine the procedures used to train the interviewers and coders used in the administration and scoring of the CDP-MD. Because the CDP-MD is administered as an interactive interview, there is a need to insure that all interviewers are trained to criteria. Specifically, the interviewers should be able to match the subject's 
responses as to category types as well as to match the subject's tone of voice and general attitude.

The results of Study 2 indicated that the CDP-MD is successful in identifying the use of critical skills in problem solving and decision making. As expected, few of the subjects were identified as Critical, since the use the of critical competencies used in moral decision making and problem solving are relatively uncommon (Pollard, 1991). This study, however, identified the use of different response patterns in subjects. Interestingly, in this sample the most frequent pattern was Undifferentiated on Critical Thinking and Accommodating on Critical Discussion, indicating that few subjects used critical cognitive competencies on their own, while showing a tendency to agree or integrate their responses with those of the interviewer during the discussion part of the interview.

The preliminary psychometric analyses showed that test-retest reliability is robust for the CDP-MD. This results will be useful in evaluating the reliability of this instrument as a pre- and post-assessment measure in research aimed at training subjects in the use of critical cognitive and communicative skills. Inter-rater reliability for the Critical Thinking Subscale was also adequate. The low inter-rater reliability results for the Critical Discussion Subscale suggest that there is a need to further train and calibrate coders. The responses to this subscale tend to be longer and more convoluted, with the subjects using lengthier and more complicated operations and actions. These operations and actions may be more difficult to recognize and categorize. Future research should address the issue of coder training and constant re-calibration.

The results of the item analyses, although disappointing, were not unexpected, 
since the measure utilizes only 4 dilemmas in each subscale. The small number of items, combined with the low frequency in the use of the critical competencies already mentioned may be underestimating these values.

Although still in the preliminary stages of development and validation, the CDPMD shows the promise of being able to assess the use of the critical cognitive and communication skills necessary in the resolution of "ill-structured" problems. The shortcomings of the CDP-MD are tempered by the scarcity of instruments designed to assess the use of these skills and capacities. Future research should focus on refining the coding procedures to increase their reliability, as well as on developing a more streamlined method of administration and recording that will be more amenable to nonresearch settings. 


\section{References}

Brabeck, M. M., \& Wood, P. K. (1985). Cross-sectional and longitudinal evidence for differences between well-structured and ill-structured problem-solving abilities. In M. L. Commons, C. Armon, L. Kohlberg, F. Richards, T. A. Grotzer, \& J. D. Sinnott (Eds), Adult development: Models and methods in the study of adolescent and adult thought. New York: Praeger.

Bransford, J., Sherwood, R., Vye, N., Rieser, J. (1986). Teaching thinking and problem solving. American Psychologist, 41, 1078-1089

Churchman, C. W. (1971). The design of inquiring systems: Basic concepts of systems and organizations. New York: Basic Books.

Davis, D. (1993). Unpublished undergraduate honors thesis, Florida International University, Miami.

Glaser, R. (1984). Education and thinking: The role of knowledge. American Psychologist, 39, 93-104.

Greeno, J. G. (1989). A perspective on thinking. American Psychologist, 44, 134-141.

Kitchener, K., \& King, P. (1981). Reflective judgement: Concepts of justification and their relationship to education. Journal of Applied Developmental Psychology, 2, 89116.

Kurtines, W. (1984). Moral behavior as rule governed behavior: A psychosocial role theoretical approach to moral behavior and development. In W. Kurtines \& J. L. Gewirtz (Eds.), Morality, moral behavior, and moral development. New York: John Wiley \& Sons, 303-324. 
Kurtines, W. (1987). Psychosocial theory as a nomotic science. In W. Kurtines \& J. L. Gewirtz (Eds.), Moral development through social interaction. New York: John Wiley \& Sons.

Kurtines, W. (1995). Psychosocial development: A co-constructivist perspective. Unpublished manuscript, Florida International University, Miami.

Kurtines, W. (1991). The Moral Identity Scale; Manual. Unpublished manuscript, Florida International University, Miami.

Kurtines, W. M., Arrufat, O., \& Davis, D. L. (1995). Critical Decision Making and Problem Solving Scale - Moral Dilemma (CDP-MD) manual. Unpublished manuscript, Florida International University, Miami.

Kurtines, W. M., Berman, S. L., Ittel, A., \& Williamson, S. (1995) Moral development: A co-constructivist perspective. In W. M. Kurtines \& J. L. Gewirtz (Eds.), Moral development, an introduction. Boston: Allyn \& Bacon.

Kurtines, W., Mayock, E., Pollard, S. R., Lanza, T., \& Carlo, G. (1991). Social and moral development from the perspective of psychosocial theory. In Kurtines, W. \& Gewirtz, J. G. (Eds.) Handbook of moral behavior and development: Theory, research, and application (Vol. 1). New York: Erlbaum \& Associates.

McCarthy, T. (1981). The critical theory of Jurgen Habermas. Boston: MIT Press.

Norris, S. P. (1989). Can we test validly for critical thinking? Educational Researcher, 18, 21-26.

Norris, S. P., \& Ennis, R. H. (1989). Evaluating critical thinking. Pacific Grove, CA: Midwest. 
Pollard, S. R., (1991). The development and validation of an assessment instrument for communicative style. Unpublished Masters Thesis, Florida International University, Miami.

Pollard, S. R., Kurtines, W., Carlo, G., Dancs, M., \& Mayock, E. (1991). Moral education from the perspective of psychosocial theory. In Kurtines, W., \& Gewirtz, J. L. (Eds.), Handbook of Moral Behavior and Development (Vol. 3). New York: Erlbaum \& Associates.

Siegel, H. (1988). Educating reason: Rationality, critical thinking, and education. London: Routledge.

Williamson, S. (1992). The development and validation of a measure of critical cognitive style. Unpublished Masters Thesis, Florida International University, Miami.

Young, R. E. (1980). Fostering critical thinking: New directions for teaching and learning. San Francisco: Jossey-Bass. 
Tables 
Table 1

Comparison of response times ( in seconds) between the less comprehensive and the more comprehensive cognitive probes used for the Critical Thinking Subscale.

\begin{tabular}{|c|c|c|c|c|c|}
\hline \multicolumn{3}{|c|}{ Study 1} & \multicolumn{3}{|c|}{ Study 2} \\
\hline Dilemma 2 & Dilemma 3 & Dilemma 4 & Dilemma 2 & Dilemma 3 & Dilemma 4 \\
\hline .0072 & .0046 & .1386 & .1319 & .1723 & .0943 \\
\hline .0094 & .0055 & .1777 & .2546 & .2197 & .2483 \\
\hline .0044 & .0052 & .0047 & .2519 & .5545 & .4786 \\
\hline .1188 & .1419 & .0835 & .5291 & .1881 & .2709 \\
\hline .3917 & .0088 & .3356 & .5612 & .3471 & 1.1498 \\
\hline .0329 & .0126 & .0065 & .2975 & 1.0631 & .5744 \\
\hline .0145 & .0141 & .0108 & .2485 & .3182 & .2312 \\
\hline .2407 & .1938 & .1833 & .3685 & .2489 & .2347 \\
\hline .0110 & .0074 & .2529 & 1.1935 & .3228 & .5052 \\
\hline .2228 & .0274 & .2554 & 1.1149 & 1.1307 & .3333 \\
\hline .0283 & .0486 & .0597 & .2130 & .1696 & .1876 \\
\hline .1938 & .0327 & .0319 & .3025 & .1407 & .4680 \\
\hline .2569 & .1579 & .1903 & .5763 & .3133 & .4856 \\
\hline .0118 & .2119 & .0143 & .2865 & .1997 & .2532 \\
\hline .2598 & .4918 & .3065 & 1.0312 & .4668 & .4845 \\
\hline .3216 & .4860 & .2753 & .2810 & .4187 & .0769 \\
\hline .0112 & .0169 & .0306 & 1.0132 & .4617 & .5803 \\
\hline .2605 & .1172 & .0543 & .3542 & .5048 & .4471 \\
\hline .0147 & .0139 & .0339 & .4529 & .2431 & .5995 \\
\hline .0062 & .2104 & .0097 & .2833 & .4830 & .2460 \\
\hline $\begin{aligned} \bar{x} & =.1209 \\
\mathrm{~s} & =.1314\end{aligned}$ & $\begin{aligned} \bar{x} & =.1104 \\
\mathrm{~s} & =.1495\end{aligned}$ & $\begin{aligned} \bar{x} & =.1228 \\
\mathrm{~s} & =.1142\end{aligned}$ & $\begin{aligned} \bar{x} & =.4873 \\
\mathrm{~s} & =.3305\end{aligned}$ & $\begin{aligned} \bar{x} & =.3983 \\
\mathrm{~s} & =.2699\end{aligned}$ & $\begin{aligned} \bar{x} & =.3975 \\
\mathrm{~s} & =.2397\end{aligned}$ \\
\hline
\end{tabular}


Table 2

\section{Patterns of Global Scores}

\begin{tabular}{|c|c|c|}
\hline \multirow[b]{2}{*}{ Subject No. } & \multicolumn{2}{|c|}{ Global Scores } \\
\hline & Critical Thinking Subscale & Critical Discussion Subscale \\
\hline 1 & Undifferentiated & Argumentative \\
\hline 2 & Undifferentiated & Critical \\
\hline 3 & Critical & Accommodator \\
\hline 4 & Undifferentiated & Accommodator \\
\hline 5 & Critical & Accommodator \\
\hline 6 & Undifferentiated & Argumentative \\
\hline 7 & Critical & Critical \\
\hline 8 & Undifferentiated & Accommodator \\
\hline 9 & Undifferentiated & Accommodator \\
\hline 10 & Undifferentiated & Critical \\
\hline 11 & Undifferentiated & Accommodator \\
\hline 12 & Undifferentiated & Argumentative \\
\hline 13 & Undifferentiated & Undifferentiated \\
\hline 14 & Undifferentiated & Accommodator \\
\hline 15 & Undifferentiated & Accommodator \\
\hline 16 & Undifferentiated & Undifferentiated \\
\hline 17 & Undifferentiated & Argumentative \\
\hline 18 & Critical & Critical \\
\hline 19 & Critical & Accommodator \\
\hline 20 & Undifferentiated & Accommodator \\
\hline
\end{tabular}


Table 3

Test-retest reliability

\begin{tabular}{|c|c|c|c|c|}
\hline \multirow{2}{*}{$\begin{array}{c}\text { Subject } \\
\text { No. }\end{array}$} & \multicolumn{2}{|c|}{ Test } & \multicolumn{2}{c|}{ Retest } \\
\cline { 2 - 5 } & Thinking & Discussion & Thinking & Discussion \\
\hline \hline 1 & Critical & Accommodator & Undifferentiated & Argumentative \\
\hline 2 & Undifferentiated & Argumentative & Undifferentiated & Critical \\
\hline 3 & Critical & Argumentative & Critical & Undifferentiated \\
\hline 4 & Undifferentiated & Accommodator & Undifferentiated & Accommodator \\
\hline 5 & Undifferentiated & Accommodator & Critical & Accommodator \\
\hline 6 & Undifferentiated & Argumentative & Undifferentiated & Argumentative \\
\hline 7 & Critical & Critical & Critical & Critical \\
\hline 8 & Undifferentiated & Accommodator & Undifferentiated & Accommodator \\
\hline 9 & Undifferentiated & Accommodator & Undifferentiated & Accommodator \\
\hline 10 & Undifferentiated & Accommodator & Undifferentiated & Critical \\
\hline
\end{tabular}


Appendixes 
Appendix A

Moral Dilemmas-Interview/Protocol Worksheet 
Critical Decision Making and Problem Solving Scale - Moral Dilemma

(CDP-MD) Interview Protocol/Worksheet

PART 1: Critical Thinking (Items I -IV)

Getting the Interview Started -- Have the subject begin by taking a few minutes to read the background information and first dilemma as indicated on the CDP-MDInterviewee's Copy.

Instructions to Participants (Read to subjects):

In Part 1 of this interview we are interested in how people think when they are making decisions and solving problems involving moral choices. We are going to be discussing some moral dilemmas. I am going to read them to you one at a time and then ask you questions about what you would do and why you would make that decision. If you need to spend more time with the readings you are welcome to look at each one privately after I read it aloud. Any questions? Let's begin. 


\section{Lying}

The adventures told here begin on a fine morning, early in the spring. Rob, the more enterprising of the three, had decided to try a hand at farming. Rob had purchased a few acres of farmland not far from where they lived and, since Hobbits are a close knit people, Sam and Dale volunteered to help get the farm started.

As they were walking along the road to the farm, Rob and Sam began talking about Sam's father. Sam had been on a trip to a far a way land that took several weeks. While he was away, his father had become seriously ill of an incurable disease and had died. Sam did not find out about his father's death until he returned. Because Hobbits are very close, Rob had spent the last few days taking care of Sam's father. Sam's father had suffered a great deal during his last few days. Rob and Sam were talking about his father, and Sam asked Rob how his father's last days had been and if he had suffered much. Rob thought about what to tell Sam. On the one hand, he could tell Sam the truth, that his father had suffered a lot during his last days. Now, Rob knew that Sam felt very bad about his father's death and telling him that he had suffered would only make him feel worse. On the other hand, he could tell Sam that his father had not suffered very much. This would not be the truth, but Sam would probably not feel as bad if he did not think his father had suffered. Sam would never find out the truth if Rob did not tell him because there was no one else with his father during the last days. Rob was not sure about what to do so he considered his choices. On the one hand, he felt he had a duty or obligation to tell Sam the truth even though it would hurt him. On the other hand, he felt that by not telling him the truth he would spare him some pain.

If you were Rob, what would you do?

1) Tell the truth.

2) Don't tell the truth.

Why?

a) "In this study we are interested in finding out as much as we can about how people make choices. Therefore, we are especially interested in as much as you could tell us about how you made this choice"

b) "Are there any more details or information that you think might help us to understand how you made your choice?"

c) "Do you want to say more?" 


\section{Fair Day's Pay}

Rob, Sam, and Dale continued on their journey and soon arrived at the farm. The farm was obviously going to need a lot of work. The three Hobbits set to work and the farm quickly began to take shape.

As the day drew to a close, work on the farm stopped. Hobbits, we noted earlier, delight in receiving as well as giving presents and Rob, grateful for the help of Sam and Dale, decided to surprise them each with a nice present. Rob had five gold coins that he wanted to give them as presents for helping. A Hobbit gold coin is quite valuable. The trouble is that Rob could not decide how to share the coins. Both Hobbits had worked all day but Sam had worked harder than Dale. Rob felt he had an obligation to reward Sam more because he had worked harder than Dale. However, Rob also knew that Dale had been saving money for an operation that his mother needed to restore her eyesight, which was failing rapidly. Dale needed only three more gold coins. Rob was not sure about what to do so he considered his choices. On the one hand, he could give Dale three coins and Sam two, even though Sam had worked harder than Dale. That way Dale would have enough for his mother's operation. On the other hand, he could give Sam three coins and Dale two, even though Dale needed the extra coin for the operation. That way Sam would be rewarded for his extra work.

If you were Rob what do you think you would do?

1) Give three to Dale and two to Sam.

2) Give three to Sam and two to Dale.

Why?

a) "In this study we are interested in finding out as much as we can about how people make choices. Therefore, we are especially interested in as much as you could tell us about how you made this choice"

b) "Are there any more details or information that you think might help us to understand how you made your choice?"

c) "Do you want to say more?" 


\section{Breaking a Promise}

After Rob had given both Sam and Dale their presents, the three Hobbits began to prepare dinner. And it was a splendid supper indeed, for all of the hard work and fresh air had given the Hobbits a hearty appetite. Later, while sitting on the porch, Sam told Rob that he had found a magic black mushroom in the field. Black mushrooms were said to have many different types of powers. It has been said that one bite of a black mushroom could make someone feel very happy. Black mushrooms, however, have also been said to make Hobbits act in strange ways, sometimes even causing them to harm themselves. Now, while Sam had a warm and friendly disposition, he was also noted for being very impulsive and for doing foolish things. Consequently, Sam asked Rob to keep the black mushroom for him. However, before giving Rob the mushroom, Sam made Rob swear a double solemn oath, which Hobbits take very seriously, to give him the black mushroom back whenever he asked for it.

Later on in the evening, in the middle of a fitful sleep, Sam woke up. He had been feeling very bad about his father, and he asked Rob to give him the black mushroom back because he wanted to eat some. Rob was not sure about what to do so he considered his choices. On the one hand, he felt that he had an obligation to give him the mushroom back because he had made a solemn promise to do so. On the other hand, he felt that if he did give it back Sam might do something to hurt himself.

If you were Rob, what would you $d o$ ?

1) Give the mushroom back.

2) Keep the mushroom.

Why?

a) "In this study we are interested in finding out as much as we can about how people make choices. Therefore, we are especially interested in as much as you could tell us about how you made this choice"

b) "Are there any more details or information that you think might help us to understand how you made your choice?"

c) "Do you want to say more?" 


\section{You Broke It You Bought It}

Work on the farm continued. There was much to be done and the Hobbits worked with great enthusiasm. In fact, Dale and Sam even went so far as to go into town to borrow a plow from The Merchant in order to speed up clearing the field. While they were plowing together in the field, Sam began talking to Dale about the trip he had taken to a far away land, in spite of Dale's protests that he should pay more attention to their task. Suddenly, the plow struck a huge boulder and the blade broke. The plow was ruined. The Hobbits took it back to The Merchant and The Merchant asked Rob who was going to pay for the plow. Now, Hobbits do not have a formal court system in the same way that we "Big Folk" do. When a Hobbit violates one of "The Rules," as they refer to their laws, which have been handed down since ancient times, it falls upon the master of the house to serve as a combination policeman, judge, and warden. Because Dale and Sam live on Rob's farm The Merchant demanded that Rob insure that he receive nine gold coins for the broken plow.

After listening to The Merchant, Rob decided that his claim was justified and Sam and Dale would have to pay for the plow. One would have to pay five coins and the other would have to pay four, but he was not sure which one should pay more. To make matters worse, "The Rules" prevented Rob from getting personally involved with the settlement. Sam had told Rob that he could only afford to pay four coins for the plow because he needed to pay off the balance of the mortgage on the house he owns in town. He had been saving all year to pay it off. The balance due was one hundred gold coins and Sam only had one hundred and four coins. If he had to pay The Merchant more than four coins he would not have enough left for his mortgage, and since it was due next week he would lose his house. Rob was not sure what to do so he considered his choices. On the one hand, he felt he had an obligation to make Sam pay more than Dale because it was Sam's carelessness that caused the plow to break. On the other hand, if he made Dale pay the extra coin Sam would not lose his house.

If you were Rob what do you think you would do?

1) Have Dale pay more than Sam.

2) Have Sam pay more than Dale.

Why?

a) "In this study we are interested in finding out as much as we can about how people make choices. Therefore, we are especially interested in as much as you could tell us about how you made this choice"

b) "Are there any more details or information that you think might help us to understand how you made your choice?"

c) "Do you want to say more?" 
PART 2: Critical Discussion (Items III-VI)

Instructions to Participants (Read to subjects) :

In Part 2 of the interview we are interested in how people talk about issues when they try to come to an agreement on what is the right thing to do. Because we have to suppose that there is a disagreement to start with, I will be taking the opposite choice on the dilemmas from whatever you take. Please make the choice that you would normally choose or the one which you feel is right. I will take the other choice and we will talk about the choices and try to come to some sort of an agreement about what to do. Any questions? We will begin by re-reading and discussing two of the previous dilemmas. 


\section{Breaking a Promise}

Initial choice: (yours or theirs)

1) Give the mushroom back (O).

2) Keep the mushroom (C).

them you
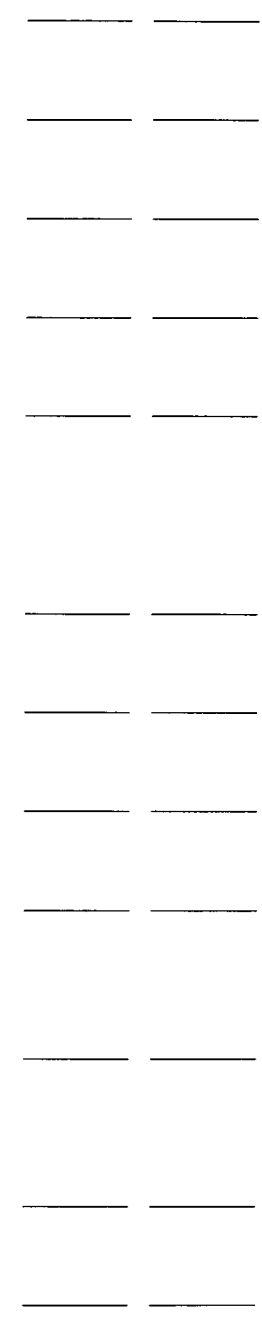

Category Types

Dilemma Specific, factual

Dilemma Specific, normative

Generalized, factual

Generalized, normative explicit

\section{Self-Oriented}

Initial Choice: Subject states/defines initial choice

Justifications: Subject states OWN justification

Paraphrases: Subject paraphrases OWN CJ

Challenges: Subject tests the validity of OWN CJ

Strategic: Subject insults; "smokescreens"

\section{Other Oriented}

Paraphrases: Subject paraphrases OTHER's CJ

Challenges: Subject tests the validity of OTHER's CJ

Entertainments: Subject entertains the validity of OTHER's CJ

Modification: Subject modifies OWN CJ toward other's without explicit acknowledgement of OTHER's CJ.

Integration: Subject modifies OWN CJ toward other's with acknowledgement of OTHER's CJ.

Outcome: Subject attempts or completes agreement

Subject requests information/clarification from OTHER

(Note: category not coded) 


\section{Breaking a Promise}

After Rob had given both Sam and Dale their presents, the three Hobbits began to prepare dinner. And it was a splendid supper indeed, for all of the hard work and fresh air had given the Hobbits a hearty appetite. Later, while sitting on the porch, Sam told Rob that he had found a magic black mushroom in the field. Black mushrooms were said to have many different types of powers. It has been said that one bite of a black mushroom could make someone feel very happy. Black mushrooms, however, have also been said to make Hobbits act in strange ways, sometimes even causing them to harm themselves. Now, while Sam had a warm and friendly disposition, he was also noted for being very impulsive and for doing foolish things. Consequently, Sam asked Rob to keep the black mushroom for him. However, before giving Rob the mushroom, Sam made Rob swear a double solemn oath, which Hobbits take very seriously, to give him the black mushroom back whenever he asked for it.

Later on in the evening, in the middle of a fitful sleep, Sam woke up. He had been feeling very bad about his father, and he asked Rob to give him the black mushroom back because he wanted to eat some. Rob was not sure about what to do so he considered his choices. On the one hand, he felt that he had an obligation to give him the mushroom back because he had made a solemn promise to do so. On the other hand, he felt that if he did give it back Sam might do something to hurt himself.

If you were Rob what do you think you would do?

1) Give the mushroom back.

2) Keep the mushroom. 


\section{You Broke It You Bought It}

\section{Initial choice: (yours or theirs)}

1) Have Dale pay more than Sam (C).

2) Have Sam pay more than Dale (O).

them you
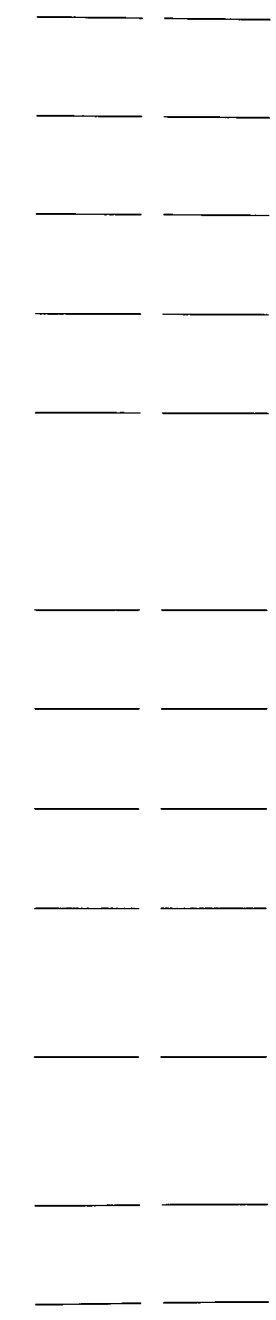

Category Types

Dilemma Specific, factual

Dilemma Specific, normative

Generalized, factual

Generalized, normative

\section{Self-Oriented}

Initial Choice: Subject states/defines initial choice

Justifications: Subject states OWN justification

Paraphrases: Subject paraphrases OWN CJ

Challenges: Subject tests the validity of OWN CJ

Strategic: Subject insults; "smokescreens"

\section{Other Oriented}

Paraphrases: Subject paraphrases OTHER's CJ

Challenges: Subject tests the validity of OTHER's CJ

Entertainments: Subject entertains the validity of OTHER's CJ

Modification: Subject modifies OWN CJ toward other's without explicit acknowledgement of OTHER's CJ.

Integration: Subject modifies OWN CJ toward other's with explicit acknowledgement of OTHER's CJ.

Outcome: Subject attempts or completes agreement

Subject requests information/clarification from OTHER

(Note: category not coded) 


\section{You Broke It You Bought It}

Work on the farm continued. There was much to be done and the Hobbits worked with great enthusiasm. In fact, Dale and Sam even went so far as to go into town to borrow a plow from The Merchant in order to speed up clearing the field. While they were plowing together in the field, Sam began talking to Dale about the trip he had taken to a far away land, in spite of Dale's protests that he should pay more attention to their task. Suddenly, the plow struck a huge boulder and the blade broke. The plow was ruined. The Hobbits took it back to The Merchant and The Merchant asked Rob who was going to pay for the plow. Now, Hobbits do not have a formal court system in the same way that we "Big Folk" do. When a Hobbit violates one of "The Rules," as they refer to their laws, which have been handed down since ancient times, it falls upon the master of the house to serve as a combination policeman, judge, and warden. Because Dale and Sam live on Rob's farm The Merchant demanded that Rob insure that he receive nine gold coins for the broken plow.

After listening to The Merchant, Rob decided that his claim was justified and Sam and Dale would have to pay for the plow. One would have to pay five coins and the other would have to pay four, but he was not sure which one should pay more. To make matters worse, "The Rules" prevented Rob from getting personally involved with the settlement. Sam had told Rob that he could only afford to pay four coins for the plow because he needed to pay off the balance of the mortgage on the house he owns in town. He had been saving all year to pay it off. The balance due was one hundred gold coins and Sam only had one hundred and four coins. If he had to pay The Merchant more than four coins he would not have enough left for his mortgage, and since it was due next week he would lose his house. Rob was not sure what to do so he considered his choices. On the one hand, he felt he had an obligation to make Sam pay more than Dale because it was Sam's carelessness that caused the plow to break. On the other hand, if he made Dale pay the extra coin Sam would not lose his house.

If you were Rob what do you think you would do?

1) Have Dale pay more than Sam.

2) Have Sam pay more than Dale. 


\section{Stealing}

\section{Initial choice: (yours or theirs)}

1) Not take the coins (O).

2) Take the coins (C).

\section{them you Self-Oriented}

Initial Choice: Subject states/defines initial choice

Justifications: Subject states OWN justification

Paraphrases: Subject paraphrases OWN CJ

Challenges: Subject tests the validity of OWN CJ

Strategic: Subject insults; "smokescreens"

\section{Other Oriented}

Paraphrases: Subject paraphrases OTHER's CJ

Challenges: Subject tests the validity of OTHER's CJ

Entertainments: Subject entertains the validity of OTHER's CJ

Modification: Subject modifies OWN CJ toward other's without explicit acknowledgement of OTHER's CJ.

Integration: Subject modifies OWN CJ toward other's with explicit acknowledgement of OTHER's CJ.

Outcome: Subject attempts or completes agreement

Subject requests information/clarification from OTHER

(Note: category not coded)

Category Types

Dilemma Specific, factual

Dilemma Specific, normative

Generalized, factual

Generalized, normative 


\section{Stealing}

After they had finished their affairs with The Merchant, the Hobbits had dinner and went to bed. They got up early the next morning and began working. While the Hobbits were working in the field, a friend of Rob's came by with news of his mother. Rob's mother had the same problem with her eyesight that Dale's had. Rob did not have the money for his mother's operation either, and he had far less than Dale. He needed one hundred gold coins. Rob's friend told him that his mother's eyesight was getting worse and that she might go blind. The only one who had that much money was Mr. Maggot, a miserly old Scrooge who lived on the next farm. Rob went over to ask him for the money, and Mr. Maggot turned him down. He said that he had worked and saved for a long time and that he wanted to keep his coins. Rob left Maggot's farm, but while he was leaving he saw that Mr. Maggot was going in to town for the afternoon. Rob had seen where Mr. Maggot kept his gold coins and he knew that he could come back in the afternoon and steal the 100 coins. Mr. Maggot had a whole room full of gold coins and would probably never even miss one hundred. Rob knew that there was no other way for him to get that many coins. He wasn't sure about what to do so he considered his choices. On the one hand, he felt he had an obligation to respect Mr. Maggot's right to keep the coins. On the other hand, he knew that if his mother did not have an operation she would probably lose her eyesight.

If you were Rob what do you think you would do?

1) Not take the coins.

2) Take the coins. 


\section{Punishment}

Initial choice: (yours or theirs)

1) Punish Sam less than the friend (C).

2) Punish Sam and the friend equally (O).

them you
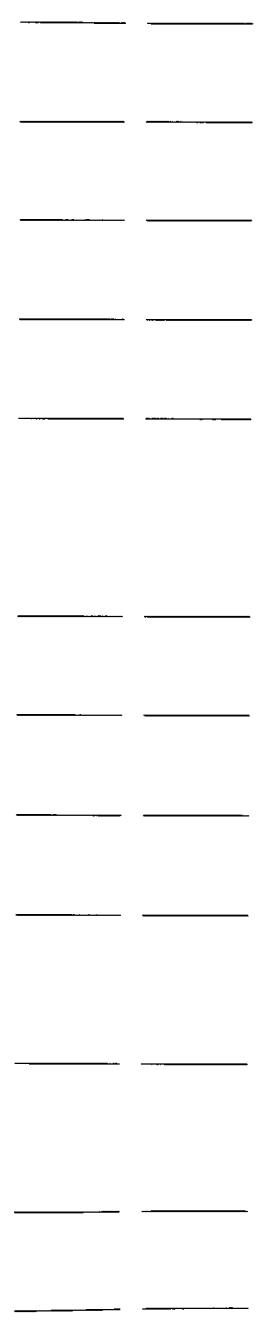

Category Types

Dilemma Specific, factual

Dilemma Specific, normative

Generalized, factual

Generalized, normative

\section{Self-Oriented}

Initial Choice: Subject states/defines initial choice

Justifications: Subject states OWN justification

Paraphrases: Subject paraphrases OWN CJ

Challenges: Subject tests the validity of OWN CJ

Strategic: Subject insults; "smokescreens"

\section{Other Oriented}

Paraphrases: Subject paraphrases OTHER's CJ

Challenges: Subject tests the validity of OTHER's CJ

Entertainments: Subject entertains the validity of OTHER's CJ

Modification: Subject modifies OWN CJ toward other's without explicit acknowledgement of OTHER's CJ.

Integration: Subject modifies OWN CJ toward other's with explicit acknowledgement of OTHER's CJ.

Outcome: Subject attempts or completes agreement

Subject requests information/clarification from OTHER

(Note: category not coded) 


\section{Punishment}

Suppose that before Rob could decide what to do, Sam, who knew about Rob's mother, had already taken the money, and that he had a friend help him. Together, they had taken 200 coins. When Mr. Maggot got back from town he discovered right away that the coins where missing (since it was his peculiar habit to count them three times a day) and went immediately to Rob's farm. At the farm he asked Rob to search the house and they found the 200 coins in Sam's room where he had hidden them. Confronted with the evidence, Sam confessed that he had indeed stolen them. Since Sam and his friend came under Rob's jurisdiction, Mr. Maggot demanded that Rob punish them for stealing the coins, because Hobbits consider stealing a very severe violation of "The Rules." Rob knew the standard punishment for an offense as severe as stealing was to serve time with one's head and hands locked in the pillories in the town square as a form of public humiliation. It was Rob's decision about how much time each Hobbit should spend in the pillories.

After confessing, Sam said that he took the coins to give his half to Rob for his mother's operation. Sam's friend, on the other hand, said that he took the coins so that he could use his half to take a vacation trip that he had always wanted. Rob knew that stealing was a very serious offense and he thought about how he might punish Sam and his friend. On the one hand, he felt that he had an obligation to sentence them both to the same amount of time as punishment because they had both committed the same offense. On the other hand, he could sentence Sam to less time because he had taken the money in order to try and do some good.

If you were Rob what do you think you would do?

1) Punish Sam less than the friend.

2) Punish Sam and the friend equally. 
Appendix B

CDP-MD Rating Form 
CDP RATING FORM

Project Session Rater Date Interviewer

Subject's Name

CRITICAL THINKING SUBSCALE

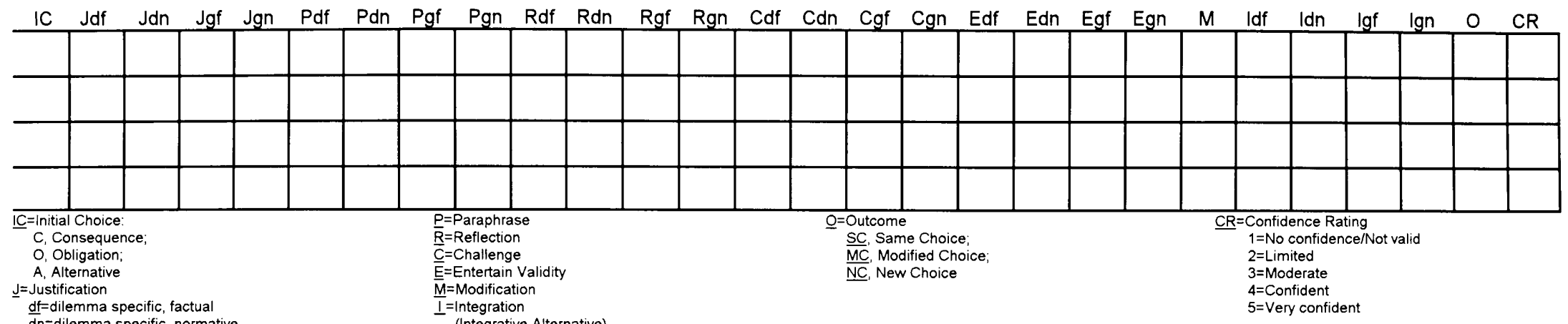

\section{CRITICAL DISCUSSION SUBSCALE}

\section{Self Oriented}

Other Oriented

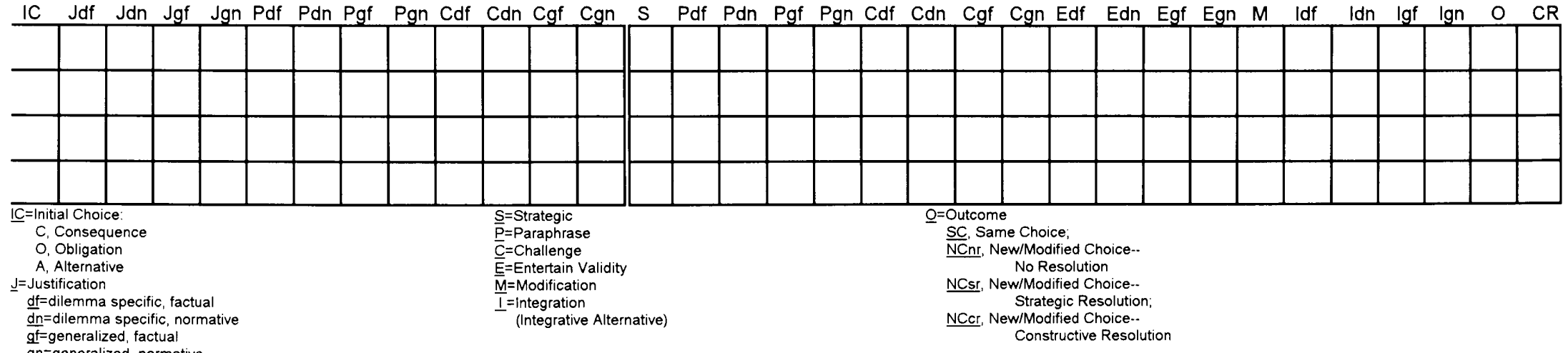

(Integrative Alternative)

Constructive Resolution 
Appendix C

Coding the CDP-MD 


\section{CODING THE CDP-MD}

The specific procedures for coding the CDP-MD described here have been developed for use with videotaped interviews ${ }^{1}$ which have been conducted using the CDP-MD Interview Protocol/Worksheet. The coding procedures are described separately for the Critical Thinking and Critical Discussion Subscales. Only operations and actions that are related to the dilemma under consideration are coded on the CDPMD. All other operations and actions are considered non-related and therefore not coded. Examples of non-related operations and actions are procedural questions from the subject about the interview, digressions on the part of the interviewer or subject to maintain, establish, or re-establish rapport, or general comments or statements by the subject (e.g., "This room is hot." or, "My class starts in 30 minutes.").

\section{Coding Part I The Critical Thinking Subscale}

The subject's responses represented in the narrative account generated by Part I of the CDP-MD are coded for categories of decision making and problem solving operations and actions adapted from the categories identified by Williamson (1992). The categories include: Justifications, Paraphrases, Reflections, Challenges, Entertainments, Modifications, and Integrations. Each of the categories is further coded for one of two category types (dilemma specific and generalized) and for two subcategory types within each type (factual and normative). Each occurrence of the use of one of the category types is recorded on the CDP Critical Thinking Rating Form using a tally or slash mark under each category for each occurrence of that category type. The subject's Initial Choice and the narrative account Outcome is also recorded on the rating form.

The purpose of the Critical Thinking Subscale is to sample the subject's use of decision making and problem solving operations and actions in an individual "moral" decision making or problem solving situation. The alternative that the subject chooses in response to the question (i.e., If you were Rob, what would you do?) is coded on the critical thinking rating form. This initial choice (which may or may not change in subsequent conversation turns) provides the focal point for coding the narrative account that follows the initial choice. Because each dilemma for the Critical Thinking Subscale is presented as an individual decision making or problem solving situation (i.e., the subject has to decide what to do), the narrative account for each dilemma consists of a series of conversation turns between the subject and the interviewer. For the Critical Thinking Subscale, the conversation turns consist of the interviewer's questions and probes and the subject's responses. Only the subject's responses are coded. The subject's response during each of the conversation turns makes up the narrative account that is coded for each occurrence of any of the categories of decision making and problem solving operations and actions.

The coding categories are described next, along with the rating codes used for each category. The coding categories (i.e., Justifications, Reflections, Paraphrases, 
Challenges, Entertainments, Modifications, and Integrations) are summary indices of the types of operations and actions that the subject uses in resolving the problem of deciding what to do. For example, in the process of making a decision, the subject can justify his/her choice, paraphrase the choice or justification, reflect on it, challenge it, entertain the validity of alternative choices or justifications, or integrate an alternate choice or justification to his/her initial choice.

\section{Rating Codes}

\section{Initial Choice (IC)}

The subject's choice of alternatives on the dilemma is recorded immediately adjacent to the dilemma number on the CDP Critical Thinking Rating Form. The subject's choice is recorded as $\mathrm{C}$ (Consequence), $\mathrm{O}$ (Obligation), or A (Alternative). When the subject makes a choice, that choice (either $\mathrm{C}, \mathrm{O}$ or A) is the subject's choice for purposes of coding. The choice that the subject does not state becomes, for purposes of coding, the "other" choice. For example, in the Breaking a Promise dilemma, if the subject states that $\mathrm{s} /$ he would give the mushroom back, the Initial Choice is recorded as $\mathrm{O}$. On the other hand, if the subject states that $\mathrm{s} / \mathrm{he}$ would keep the mushroom, the Initial Choice is recorded as C. Finally, if the subject states that $\mathrm{s} / \mathrm{he}$ would do something that is not one of the explicit choices, the Initial Choice is recorded as A. An Alternative choice usually involves a position that combines elements of the subject's choice and the "other" alternative.

\section{Coding the Narrative Account for Decision Making and Problem Solving Operations and Actions}

The subject's responses represented in the narrative account that follows the initial choice make up the content that is rated for the coding categories. The content includes any of the responses represented in the narrative account that operate on or involve action that extends, elaborates, refines, modifies, changes, or transforms either the subject's initial choice and/or justification(s) or any subsequent choices and/or justifications. This section describes the coding categories for the operations and actions that are rated on the Critical Thinking Subscale.

Justification (J) A justification is a statement that provides support for a subject's choice. A subject's statement of choice is frequently (though not always) accompanied by a justification for that choice. Each distinct or separate justification to support the choices that the subject provides during the account narrative is recorded on the CDP Critical Thinking Rating Form. For example, if the subject states that s/he would not give the mushroom back (C) and provides a dilemma specific factual justification (e.g., "because it says in the story that he might hurt himself."), the justification would be recorded in the Jdf category. If, in the next conversation turn, the subject states an additional justification that is normative and goes beyond the content of the story (e.g., "because I feel very strongly that people have a responsibility to care for each other."), 
this justification would be recorded in the Jgn category. On the other hand, if in the next conversation turn the subject repeats and/or extends, refines, or elaborates a pervious justification (e.g., "I know the story says there is only a change that he might hurt himself, but I think that any chance at all would be too great a risk."), this statement would be coded as a Paraphrase (Pdf) as discussed under the Paraphrase coding category.

For the purpose of coding justifications, a distinction is made among the following two types of justifications, dilemma specific (d) and generalized (g) and two subcategory types within each category type, factual (f) and normative (n). The same category types and subcategory types are used for the other operations and actions coded on the CDP. If a response includes more than one category type, record the occurrence of each category type within that category.

A dilemma specific justification provides a justification for a choice within the context of the framework of the fictional story. Dilemma specific justifications can be either factual (Jdf) or normative (Jdn).

A Dilemma Specific Factual Justification (Jdf) provides a factual justification for a choice by making reference to a fact or facts (e.g., the actual or foreseeable consequences of a decision or action) either contained in or implied by the written dilemma. The Jdf code is used for factual justifications that are limited to the context of the fictional story. Factual justifications can be further identified as such because they make no reference to the moral or normative issues that underlie the dilemma. In the case of the Breaking a Promise dilemma, for example, a subject might state that $\mathrm{s} / \mathrm{he}$ would give the mushroom back $(\mathrm{O})$ because he could just go get another one if he wanted (Jdf). This justification would be coded as a dilemma specific factual justification because it makes reference to a fact not contained in the dilemma but is within the realm of the story, and does not make reference to the underlying normative issue. A subject may use factual justifications to support either choice. For instance, in this dilemma, it is also plausible for a subject to argue that s/he should not give the mushroom back (C) because this is probably the only mushroom in the field or even in all of Hobbit land (Jdf).

A Dilemma Specific Normative Justification (Jdn) provides a dilemma specific normative justification for a choice. Dilemma specific justifications are normative if they make reference to the normative issue in the dilemma and they are dilemma specific if they seeks to resolve the moral issue in the context of the normative framework of the fictional story. Normative issues in moral dilemmas involve moral obligations, traditions, or claims that are in conflict. The Jdn code is therefore used if the subject justifies a choice by making reference to normative obligations, traditions, or claims provided in the dilemma. In the case of a dilemma specific justification, a subject might state that $\mathrm{s} / \mathrm{he}$ would give the mushroom back $(\mathrm{O})$ because Hobbits take solemn oaths very seriously (Jdn). This justification would be coded as dilemma specific and normative (Jdn) because it makes reference to explicit normative information given in the dilemma. 
A Generalized Factual Justification (Jgf) provides a factual justification for a choice by generalizing to a context other than the dilemma and/or the fictional story (e.g., information from "real life" situations, personal past experiences, or other contexts). Generalized factual justifications make reference to a fact or facts (e.g., the actual or foreseeable consequences of a decision or action) that is neither contained in nor implied by the written dilemma. The Jgf code is used for factual justifications that go beyond the context of the fictional story, but make no reference to the moral or normative issues that underlie the dilemma. In the case of a generalized factual justification, a subject might state that $\mathrm{s} /$ he would keep the mushroom (C) because she once gave her friend, who was drunk, the keys to his car and he caused an accident. This justification would be coded as a generalized factual justification (Jgf) because it makes reference to factual matters that go beyond the constraints of the imaginary story.

A Generalized Normative Justification (Jgn) provides a normative justification for a choice by generalizing to a context that goes beyond the normative information provided in the fictional story. In the case of a generalized normative justification, a subject might state that $\mathrm{s} /$ he would give the mushroom back because making a promise involves a moral obligation that transcends the needs of any particular situation. This justification would be coded as generalized normative (Jgn) because it makes reference to explicit normative information that goes beyond the information given in the dilemma.

Paraphrases (P) A paraphrase is a statement that repeats and/or extends, refines or elaborates a previous choice and/or justification (CJ). A paraphrase is one that includes elements of a subject's previous $\mathrm{CJ}(\mathrm{s})$. If the statement includes a justification that does not include elements of a previous justification, then it is coded as a separate justification under the appropriate category type (Jdg/fn). However, if it includes elements of a previous justification then it would be recorded as a paraphrase. An example (from Breaking a Promise) of dilemma specific normative paraphrase (Pdn) would be: "Like I said, he should give it back because he promised and Hobbits take their promises very seriously." Paraphrases can be dilemma specific or generalized and factual or normative.

Reflections (R) A reflection is a statement that goes beyond the subject's own $\mathrm{CJ}$ and includes within it a reference to the other CJ or both CJs. Reflections can be dilemma specific or generalized and factual or normative. An example (from Breaking a Promise) of Rd: If the subject states that there are really two things she could do: she could give the mushroom back $(\mathrm{O})$ or she could keep the mushroom $(\mathrm{C})$, the reflection would be recorded as a dilemma specific factual reflection (Rdf). If the reflection included a dilemma specific normative justification for the other or for both choices, then it would be recorded as a dilemma specific normative reflection ( $\mathrm{Rdn})$.

Challenges (C) A challenge is a statement that tests the validity of a previous stated CJ. Challenges require prior choices and/or justifications. For example, a subject may state that $\mathrm{s} /$ he would give the mushroom back $(\mathrm{O})$ and then challenge this choice by saying that if she made that choice $\mathrm{s} / \mathrm{he}$ and he hurt himself $\mathrm{s} / \mathrm{he}$ would be responsible for 
allowing him to get hurt (Cdn). Challenges can be factual, dilemma specific, generalized, or normative.

Entertainments (E) An entertainment involves a suspension of judgement with respect to the validity of both CJs. A statement is coded as an entertainment if the content indicates that the subject is willing to entertain the potential validity of both CJs. For purposes of coding, it is assumed that the subject is willing to entertain the validity of her choice and justification. Thus, to be coded as an entertainment, the subject must explicitly entertain the validity of the other CJ. Entertainments thus require prior reflection (the reflection can be part of the same statement or part of an earlier statement). In order for a statement to be coded as an entertainment, the subject must have explicitly acknowledged the existence of both CJs (i.e., they must have engaged in an operation or action involving the other $\mathrm{CJ}$ ). An entertainment, however, not only acknowledges both CJs, but also implicitly or explicitly acknowledges the potential validity of those CJs. Entertainments can be dilemma specific or generalized and factual or normative. For example, if the subject states that he does not want to break the promise because Hobbits take their oaths seriously but at the same time s/he wants to protect her/his friend because he may hurt himself, the statement would be recorded as a dilemma specific normative entertainment (Edn).

Modifications and Integrations ( $\mathrm{M}$ and I) A modification or integration is a statement that implicitly or explicitly attempts to satisfy both CJs. For example, a subject may state that $\mathrm{s} /$ he would give the mushroom back $(\mathrm{O})$ and then tie Sam up so he could not eat it (C). This choice allows for the actual promise to be kept and also keeps Sam from hurting himself. Modifications and integrations allow for less extreme choices by entertaining the validity of the other choice.

When a modification or integration occurs as the subject's initial choice, it is recorded as an Alternative initial choice (IC-A). When a modification or integration occurs after an initial $\mathrm{C}$ or $\mathrm{O}$ choice has been stated, it is not recorded as an initial choice, but as a Modification or Integration under the M or I category.

A modification or integration may or may not include a justification. For example (from Breaking a Promise)

\section{With justification.}

"My tendency would be to keep the promise and give the mushroom back, but I think I would tie him up so he wouldn't hurt himself.

Without justification.

"I think I would give it back and tie him up." 
Modification (M) A statement is coded as a modification if it comes after the subject has reflected upon, challenged, or entertained the other CJ and involves an implicit recognition of the other CJ. That is, it contains facts/details which change/emerge in direct response to the subject's previous operations and actions.

Integration (I) A statement is coded as an integration if it comes after the subject has reflected upon, challenged, or entertained the other $\mathrm{CJ}$ and includes an explicit recognition of the other $\mathrm{CJ}$.

Modifications and integrations may be dilemma specific or generalized and factual or normative, but all types of modifications are recorded under the $\mathrm{M}$ category.

\section{Outcome (O)}

Outcome $(\mathrm{O})$ is used to code the outcome of the narrative account for each dilemma. $\mathrm{O}$ is coded for three categories:

Same Choice (SC) if the subject has the same choice at the end of the narrative account as his/her initial choice.

Modified Choice (MC) if the subject's initial choice remains the same, but is modified or transformed during the narrative account.

New Choice (NC) if the changes his/her choice during the narrative account.

\section{Confidence Rating (C/R)}

The rater also makes an evaluation of his/her confidence that the quality and/or quantity of information contained in the video tape was sufficient or adequate to provide the basis for a valid evaluation of each of the dilemma account narratives.

$1=$ No confidence/Not valid

$2=$ Limited

$3=$ Moderate

$4=$ Confident

$5=$ Very confident

\section{Coding Part II: \\ The Critical Discussion Subscale}

The subject's responses represented in the discussion generated by Part II of the CDP-MD are coded for categories of decision making and problem solving operations and actions adapted from the categories identified by Pollard (1992). The categories include: Justifications, Paraphrases, Challenges, Strategic, Entertainments, and Alternatives. Each of the categories is further coded for one of two category types 
(dilemma specific and generalized) and for two subcategory types within each type (factual and normative). Each occurrence of the use the categories is recorded on the CDP Critical Discussion Subscale Rating Form using a tally or slash mark under each category for each occurrence of that category. The subject's Initial Choice and the discussion Outcome is also recorded on the rating form.

The purpose of the Critical Discussion Subscale is to sample the subject's use of decision making and problem solving operations and actions in a shared "moral" decision making or problem solving context. The alternative that the subject chooses in response to the first question (i.e., If you were Rob, what would you do?) is coded on the Critical Discussion Rating form. The cognitive probe, "Why?," is not asked. This initial choice (which may or may not change in subsequent conversation turns) provides the focal point for coding the discussion that follows the initial choice. Because each dilemma for the Critical Discussion Subscale is presented as a shared decision making or problem solving situation (i.e., the subject and the interviewer have to try to agree about what to do), the responses to each dilemma consist of a series of conversation turns between the subject and the interviewer. For the Critical Discussion Subscale, the conversation turns consist of the subject's responses and the interviewer's "matched" responses. Only the subject's responses are coded. The subject's response during each of the conversation turns is coded for each occurrence of any of the categories of communicative operations and actions.

The coding categories are described next along with the rating codes used for each category. The coding categories (i.e., Justifications, Paraphrases, Challenges, Strategic, Entertainments, and Integrations) are summary indices of the types of operations and actions that the subject uses in resolving the problem of making a shared decision about what to do. For example, in the process of making a shared decision, the subject can justify his/her choice, paraphrase his her own CJ or the interviewer's CJ, challenge his/her $\mathrm{CJ}$ or the interviewer's $\mathrm{CJ}$, entertain the validity of the interviewer's CJ, or integrate an alternate choice or justification to his/her initial choice.

\section{Self and Other Orientated Communicative Operations and Actions}

The coding categories for Part II are somewhat more complex than Part I. The coding categories include a number of the same basic categories (J, P, C, E, M, I) as described in Part I, plus additional categories that are used for coding Part II. The coding categories are more complex because Part II is designed to simulate a discussion. As part of the discussion, both the subject's and the interviewer's statements can be directed at either their own or the other's CJ.

Coding a subject's decision making and problem solving operations and actions as either self oriented or other oriented is based on the verbal content of the subject's statements. Operations and actions directed toward a speaker's own CJ are coded as self oriented (indicated in the coding categories by the letter "s"). Operations and actions directed toward the interviewer's $\mathrm{CJ}$ are coded as other oriented (indicated in the coding 
categories by the letter "o"). An operation or action is coded as other oriented if the content explicitly involves an operation or action directed toward the other CJ (i.e., the interviewer's).

\section{Rating Codes}

\section{Initial Choice (IC)}

The subject's choice on the dilemma is recorded immediately adjacent to the dilemma number on the CDP/CPS Critical Discussion Rating Form. The subject's choice is recorded in the same way that was described for coding critical thinking.

\section{Coding the Discussion for Decision Making and Problem Solving Operations and Actions}

The subjects responses represented in the discussion that follows the initial choice make up the content that is rated for the category codes. The content includes any of the responses represented in the discussion account that operate on or involve action that extends, elaborates, refines, modifies, changes, or transforms either the subject's or the interviewer's initial choice or subsequent choices and or justifications. This section describes the operations and actions that are rated for on the Critical Discussion Subscale.

\section{Self Oriented}

All of the operations and actions described in this section are self-oriented because they involve operations and actions directed toward the subject's own CJ.

Justification (J) Each distinct or separate justification that the subject provides to support his/her choice is recorded on the CDP Critical Discussion Rating Form. For example, if the subject states that $\mathrm{s} /$ he would give the mushroom back $(\mathrm{O})$ and provides a justification, the justification would be recorded in the $\mathrm{J}$ category. For the purpose of coding justifications, the same distinction is made among types of justification that was described for coding critical thinking: dilemma specific (d) or generalized (g) and factual (f) or normative (n) justifications.

Paraphrases (sP) A paraphrase is a statement that repeats and/or extends, refines or elaborates a previous CJ. A self oriented paraphrase is one that includes elements of a subject's previous $\mathrm{CJ}(\mathrm{s})$. If the statement does not include elements of a pervious $\mathrm{CJ}$, then it is coded as a separate or distinct justification. An example (from Breaking a Promise) of sPdn: "Like I said, he should give it back because he promised and Hobbits take their promises very seriously."

Challenges ( $\mathrm{sC}$ ) A challenge is a statement that tests the validity of a previous statement. Challenges can be either self-oriented or other-oriented. A challenge is self 
oriented when the speaker challenges his/her own CJ. An example (from Breaking a Promise) of a Cdf would be: "Oh, I would give it back because I promised. But wouldn't I feel lousy if he ate it and then jumped off a bridge or something?" In addition to being either self-oriented or other-oriented, challenges can also be dilemma specific or generalized and factual or normative.

Strategic (S) A statement is strategic if it involves the use of power, force, intimidation, deception, or manipulation in order to reach an agreement in the absence of a shared understanding. An example of manipulation and intimidation would be the use of denigrating language (from Breaking a Promise). "Oh, so you would give it back because of an idiotic promise." An example of deception would be pretending an agreement exists when one does not (from Breaking a Promise). "Oh, did I say I would give it back? I guess I really meant that I would keep it. So I guess we agree after all."

\section{Other Oriented}

All of the operations and actions described in this section are other-oriented because the involve operations and actions directed toward the interviewer's CJ.

Paraphrases (oP) A paraphrase is a statement that repeats and/or extends, refines or elaborates a previous CJ. An other oriented paraphrase is one that includes elements of the other's CJ(s). If the statement does not include elements of the other's CJ, then it is coded as a self oriented paraphrase. A paraphrase can only be coded as other oriented if it occurs after the interviewer states a CJ. An example (from Breaking a Promise) of a oPdn would be: "Oh, so you would give it back because you promised." If the subject states what $\mathrm{s} /$ he anticipates to be the other's $\mathrm{CJ}$, then the action is a Reflection. ${ }^{2}$ Paraphrases can be dilemma specific or generalized and factual or normative.

Challenges (oC) A challenge is other-oriented when it challenges the other $\mathrm{CJ}$. An example (from Breaking a Promise) of an oCdf: "Oh, so you would give it back because you promised. But wouldn't you feel lousy if he ate it and then jumped off a bridge or something?" Challenges can be dilemma specific or generalized and factual or normative.

Entertainments (E) An entertainment is a statement that involves the entertainment of the potential validity of both CJs in the dilemma. In order for a statement to be coded as an entertainment, the subject must have explicitly acknowledged the existence of both CJs, i.e., the subject must have engaged in an prior other-oriented Paraphrase $(\mathrm{oP})$ or other-oriented challenge $(\mathrm{oC})$ or include a oP or oC in the entertainment. An entertainment, however, not only acknowledges both $\mathrm{CJ}$ s, it also implicitly or explicitly acknowledges the potential validity of those CJs. Entertainments can be dilemma specific or generalized and factual or normative. For example, if the subject states that $\mathrm{s} /$ he does not want to break the promise because Hobbits take their oaths seriously but at the same time s/he wants to protect her/his friend because he may 
hurt himself, the statement would be recorded as a dilemma specific normative entertainment (oEdn).

Modifications and integrations ( $\mathrm{M}$ or I) Other-oriented modifications and integrations ( $\mathrm{M}$ or I occur after the subject has given a $\mathrm{CJ}$ and after the interviewer has also given a $\mathrm{CJ}$.

Modification (M) A statement is coded as a modification if it comes after the interviewer has given a $\mathrm{CJ}$ and if it includes an implicit recognition of the interviewer's $\mathrm{CJ}$. That is, it contains facts/details which change/emerge in direct response to the content of the interviewer's CJ.

An example (from Breaking a Promise) of $M$ :

"I'd keep it and give it back to him the next morning." The interviewer responds with a matched modification, "I'd give it to him then, but I would watch him so he wouldn't hurt himself." The subject then changes his/her modification to, "So, I'd keep it and give it back to him as soon as he was feeling better." This would be coded as $M$ because the modification changes in response to the interviewer's response, but contains no explicit reference to the content of the interviewer's CJ.

Integration (I) A statement is coded as an integration if it is paired with or in close proximity to an explicit reference to the other's $\mathrm{CJ}$ as justification for the integration. In order for a statement to be coded as an integration, the subject must have explicitly acknowledged the existence of both CJs, i.e., the subject must have engaged in a prior $\mathrm{oP}, \mathrm{oC}$, or $\mathrm{oE}$ or included one of them in the accommodation.

Example (from Breaking a Promise) of Idn:

"I'd keep it and give it back to him the next morning." The interviewer responds with a matched modification, "I'd give it to him then, but I would watch him so he wouldn't hurt himself." The subject then changes his/her CJ and explicitly acknowledges doing it as an accommodation to the interviewer's CJ, "So, I'd keep it and give it back to him as soon as he was feeling better, but I would tell him why I was doing it. That way he would know I was doing it so he wouldn't hurt himself." This would be coded as a dilemma specific normative integration (Idn) because the subject changes in response to the interviewer's CJ and provides explicit reference to the content of the interviewer's $\mathbf{C J}$.

Integrations may be dilemma specific or generalized and factual or normative.

\section{Outcome (O)}

Outcome $(\mathrm{O})$ is used to code the outcome of the discussion of each dilemma. O is coded for four categories: 
Same Choice (SC) if the subject has the same choice at the end of the discussion as his/her initial choice.

New/Modified Choice--No Resolution (NCnr) if the subject changes or modifies his/her choice during the discussion, but does not reach an agreement with the interviewer about what to do.

New/Modified Choice--Strategic Resolution (NCsr) if the subject changes or modifies his/her choice during the discussion and reaches a strategic resolution with the interviewer about what to do. A strategic resolution is an agreement about what to do in the absence of any explicit discussion on the part of the subject that recognizes the potential validity of the other CJ. That is, a strategic resolution occurs when the subject agrees with the interviewer without the prior use of E or I. For example, a subject agrees with the interviewer just to end the discussion, but has not engaged in any communicative operations or actions that indicate that $\mathrm{s} /$ he has considered the potential validity of the interviewer's $\mathrm{CJ}$.

New/Modified Choice--Constructive Resolution (NCcr) if the subject changes or modifies his/her choice during the discussion and reaches a constructive resolution with the interviewer about what to do. A constructive resolution is one that includes explicit discussion on the part of the subject that recognizes the potential validity of the other's claim. That is, a constructive resolution occurs when the resolution is preceded by the subject's use of $\mathrm{E}$ or I.

\section{Confidence Rating (C/R)}

The rater also makes an evaluation of his/her confidence that the quality and/or quantity of information contained in the video tape was sufficient or adequate to provide the basis for a valid evaluation of each of the dilemma discussion narratives.

$1=$ No confidence/Not valid

$2=$ Limited

$3=$ Moderate

4=Confident

$5=$ Very confident 
Appendix D

Administering Part II of the CDP-MD 


\section{PROCEDURES FOR ADMINISTERING PART II OF THE CDP-MD}

\section{Prerequisite Skills for Interviewer}

a) The interviewer must have an understanding of the test stimuli (moral dilemmas) as well as an understanding of the dilemma choices (consequence versus obligation). The interviewer must be proficient at recognizing prototypical consequence and obligation justifications associated with these choices.

b) The interviewer must be proficient at generating prototypical justifications for all possible choices.

c) The interviewer must be familiar with all of the categories of decision making and problem solving operations and actions to be able to match them.

\section{Matching Categories}

Follow this procedure for all dilemmas on the Critical Discussion Subscale.

After reading the instructions aloud, the interviewer reads the moral dilemmas one at a time to the subject. Following each reading, and after the subject has made a choice, the interviewer begins the procedure of matching the subject's operations and actions as discussed in the manual and this appendix.

1) The interviewer must attempt to match each operation and action of the subject by same category, but with reference to the opposite choice. To do this, simply identify the orientation (self or other), category (Choice, Justification, Paraphrase, Challenge, etc.) and type (Factual, Dilemma Specific, Generalized, or Normative) and then match with the same orientation, category, and type but with respect to opposite choice $(\mathrm{C}$ or $\mathrm{O})$.

2) Follow this procedure until one of the following criteria is met:

a) the subject ends the episode.

b) the subject reaches a resolution with the interviewer or agrees that it is not possible to agree.

c) the episode lasts for 3-4 conversation turns or ten minutes without being resolved.

Matching categories is simple enough, but there are some rules that constraint the procedure.

Non-related speech acts (such as "small talk") are not coded, but feel free to match them, since this may ease tension and make things more realistic and interesting for you and the subject. 
If the subject responds with more than one category in the same conversation turn try to match all categories in the same order in which the subject responded. For example, if in the same conversation turn the subject "drops" from an other oriented response to a self oriented response, match the other oriented response first and then match the self oriented response second. It may not always be possible to match in the same order, but the interviewer should at least be able to match all categories of response. It may be possible to keep track of the order of multiple categories in single conversation turns by using different pencil marks or ordinal numbering on the summaries of response categories that follow each dilemma. But if you lose track of the order at least identify and match all of the categories.

Occasionally you will be interrupted by the subject while attempting to match a response that she made in the previous conservation turn. Most commonly, such interruptions are elaborations of immediately previous operations or actions by the subject, that is, they are of the same category. If this is the case, on the next conversation turn you should continue matching the response, but not the interruption. If the interruption is in a different category from the immediately previous speech act, then you should match it in the next conversation turn, but again not the interruption.

\section{Matching other oriented responses}

A subject's response cannot be other oriented until you have had a chance to state your CJ (Choice and/or Justification for choice). If the subject's response includes your CJ before you have a chance to state it, then it is self oriented even though it anticipates your CJ. The subject is "guessing" what your CJ will be, but the response is not actually other oriented because you have not communicated your $\mathrm{CJ}$. If the subject's response includes your CJ after you have explicitly stated it, then it is other oriented.

Matching an other-oriented Challenge (i.e., a challenge to your $\mathrm{CJ}$ ) requires an additional step prior to matching. If a subject challenges your CJ ("If you give the mushroom back and he hurts himself, you feel bad about what you did."), the first step is to respond to the challenge ("If I don't give it back I will feel bad about breaking my promise."). Then, "match" the challenge ("If you keep it, nothing will happen and he might not trust you to keep your word in the future.").

\section{Matching for qualitative aspects of communication}

In general, you must be aware of the following qualities of your subject's response and be able to match them:

1) Tone of subject's voice: is it positive, neutral, or negative?

2) Body "language:" general level of activity, body movement, and gestures. 
3) Conservation turn: approximate length and completeness of subject's conservation turn.

\section{Matching strategic action}

Some forms of strategic action are subtle, others are not. Try to match them in terms of their explicitness but with respect to the opposite choice.

Example 1 (pretty obvious)

Both the subject and interviewer have just stated their respective (opposite) choices.

Subject: "That's the stupidest thing I ever heard."

Interviewer: (matches) "Well, what you said seems pretty dumb to me."

Example 2 (somewhat more subtle)

Subject: "I would definitely lie and I don't see how any intelligent person could do otherwise."

(This also can be understood as a character attack. The subject is attempting to avoid the discussion of the issue by implying that the you are stupid if you don't agree with her.)

Interviewer: (matches) "Alright, suppose I said that I would definitely tell the truth since that's the only intelligent choice."

\section{Reading the Dilemmas}

The interviewer must read each of the dilemmas. Following each reading, the dilemmas are discussed. Read the dilemma completely, even if it is one of the dilemmas that was used in Part I of the interview. It is helpful to read it again because it assists the subject in being clear about the details of the dilemma. If the dilemma has been used before and the subject indicates that $\mathrm{s} / \mathrm{he}$ remembers, it can be read very quickly to touch on all of the main points. It is also helpful to inform the subject why you doing it (e.g., "I'll just read through the story very quickly so that we can be sure we remember the main points.").

\section{Making Choices}

The subject is always asked to make a choice first. If the subject asks you to make a choice first, (e.g., "What would you do?) simply match this response (e.g., Well..., what would you do?). 
After the subject has made his/ her choice, s/he will often though not always justify it. You make the opposite choice and either justify it or not depending on what the subject has done, i.e., you will begin the matching procedure. If the subject asks you for a justification before she has provided one, (e.g., "Why would you do that?), use the same procedure as for making choices. Simply match the response (e.g., "Well..., why would you do that?)

\section{Deception}

To not deceive the subject about the nature discussion, it is important to be sure the subject understands that the discussion is a simulation. This can be done by saying something similar to the following before making your choice: "Alright, then. Suppose that we were talking about this and I made the opposite choice. Then I would be saying that if I were Rob that (and then state the opposite choice)..." 